\title{
Multitopic Ligand Design: A Concept for Single-Source Precursors
}

\author{
Fabienne Gschwind, ${ }^{\dagger}$ Olha Sereda, ${ }^{\ddagger}$ and Katharina M. Fromm ${ }^{*} \dagger$ \\ ${ }^{\dagger}$ University of Fribourg, Department of Chemistry, Chemin du Musée 9, CH-1700 Fribourg, Switzerland, and \\ ॠCSEM Centre Suisse d'Electronique et de Microtechnique SA, CH-2002 Neuchâtel, Switzerland
}

\begin{abstract}
The multitopic ligand $\mathrm{O}, \mathrm{O}^{\prime}$-bisnicotinic acid tetraethylene glycol, L, was designed for the coordination of two distinct types of metal ions. In this work, we describe how the 0 -donor part of $L$ is used to coordinate to alkaline earth metal ions and that the $\mathrm{N}$-donor atoms of $\mathrm{L}$ bind to group 11 elements. This makes $\mathrm{L}$ a suitable ligand for the combination of both metal ion types within the same compound. This concept will be exemplified by highlighting the pure $\mathrm{Ca}^{2+}$ complexes, a $\mathrm{Cu}^{+}$-coordination polymer network, as well as the mixed-metal compound, which can be used as a single-source precursor for mixed-metal oxide materials.
\end{abstract}

\section{Introduction}

In previous works, complexes of alkaline earth metal ions were used as precursors for the synthesis of mixed-metal oxides, for example, high-Tc superconductors, focusing on the volatility of the products and their capacity of forming the target oxides. ${ }^{1-5}$ Such metal oxides find applications in many areas, such as magnetism, superconductivity, optics, and electronics. The composition of such materials can be relatively simple, as in the ferroelectric $\mathrm{BaTiO}_{3},{ }^{6}$ or more complicated, as in the superconductors $\mathrm{YBa}_{2} \mathrm{Cu}_{3} \mathrm{O}_{7-\delta}(\mathrm{YBCO})^{7}$ or $\mathrm{Bi}_{2} \mathrm{Sr}_{2} \mathrm{Ca}_{n} \mathrm{Cu}_{n+1} \mathrm{O}_{2 n+6}$ (BSCCO). ${ }^{8,9}$ Their synthesis may occur either by solid-state reactions requiring high temperatures or by milder methods such as metal organic chemical vapor deposition ((MO-)CVD) or sol-gel techniques. For (MO-)CVD, volatile compounds of the constituting metal ions are required, which are thermally stable enough for

*To whom correspondence should be addressed. E-mail: Katharina Fromm@unifr.ch.

(1) Frausto da Silva, J. J. R.; Williams, R. J. P. The Biological Chemistry of the Elemts, 2nd ed.; Oxford University Press: Oxford, U. K., 2001; Chapter 10.

(2) Fromm, K. M.; Gueneau, E. D. Polyhedron 2004, 23, 1479-1504 and references therein.

(3) Bradley, D. C. Chem. Rev. 1989, 89, 1317.

(4) Caulton, K. G.; Hubert-Pfalzgraf, L. G. Chem. Rev. 1990, 90, 969

(5) (a) Hitchcock, P. B.; Lappert, M. F.; Singh, A. Chem. Commun. 1983, 1499. (b) Bochmann, M.; Bwembya, G. C.; Grinter, R.; Powell, A. K.; Webb, K. J. Inorg. Chem. 1994, 33, 2290. (c) Campbell, J. P.; Gladfelter, W. L. Inorg. Chem. 1997, 36, 4094. (d) Bunge, S. D.; Boyle, T. J.; Pratt, H. D., III; Alam, T. M.; Rodriguez, M. A. Inorg. Chem. 2004, 43, 6035. (e) Cross, W. B.; Parkin, I. P.; O'Neill, S. A. Chem. Mater. 2003, 15, 2786. (f) Boyle, T. J.; Rodriguez, M. A.; Ingersoll, D.; Headley, T. J.; Bunge, S. D.; Pedrotty, D. M.; De'Angeli, S. M.; Vick, S. C.; Fan, H. Chem. Mater. 2003, 15, 3903. (g) Evans, W. J.; Olofson, J. M.; Ziller, J. W. Inorg. Chem. 1989, 28, 4308. (h) Edwards, D. A.; Mahon, M. F.; Molloy, K. C.; Ogrodnik, V. Inorg. Chim. Acta 2003, 349, 37. (i) Day, V. W.; Eberspacher, T. A.; Klemperer, W. G.; Liang, S. Chem. Mater. 1995, 7, 1607. (j) Miele, P.; Foulon, J.-D.; Hovnanian, N.; Cot, L. Polyhedron 1993, 12, 267.

(6) Flaschen, S. S. J. Am. Chem. Soc. 1955, 77, 6194.

(7) Edwards, P. P.; Harrison, M. R.; Jones, R. Chem. Br. 1987, 23, 692.

(8) Hazen, R. M.; Prewitt, C. T.; Angle, R. J. Phys. Rev. Lett., 1988, 60, 2

(9) Maeda, H.; Tanaka, Y.; Fukutomi, M. Jpn. J. Appl. Phys 1988, 27, 1209. stochiometric deposition as (thin) films on the substrate. ${ }^{5}$ Generally, a mixture of volatile metal compounds is used to generate the target oxide. Yet, for alkaline earth metal diketonates $^{10}$ or ketoimines, ${ }^{11}$ oligomerization as well as insufficient volatility and stability are often a problem. It was therefore interesting to combine all of the required metal atoms within one single precursor, and many efforts have been made to tailor such "single-source precursors". Yet, for example, for $\mathrm{YBa}_{2} \mathrm{Cu}_{3} \mathrm{O}_{7-\delta}$ (or even more complicated systems), no solution in the form of single-source precursors containing all three (or more) metal ions within one molecule has been found so far. Much effort has been put into the synthesis of mixed-metal alkoxides, which are revealed to be excellent precursors for MO-CVD or CVD. ${ }^{12}$ Recent results showed that it is often possible to combine as many as two different required metal ions in volatile metal organic compounds. ${ }^{13}$ For instance, the compounds $\left[\mathrm{YBa}_{3}(\mathrm{O} t \mathrm{Bu})_{6}(\mathrm{thd})_{3}\right]$

(10) (a) Gleizes, A.; Sans-Lenain, S.; Medus, D. Acad. Sci. Ser. II 1991, 313, 761. (b) Drozdov, A. A.; Troyanov, S. I. Polyhedron 1996, 15, 1731. (c) Drake, S. R.; Hursthouse, M. B.; Malik, K. M. A.; Otway, D. J. J. Chem. Soc., Dalton Trans. 1993, 2883. (d) Gleizes, A.; Drozdov, A.; Troyanov, S. Koord. Khim. 1994, 20, 922. (e) Auld, J.; Jones, A. C.; Leese, A. B.; Cockayne, B.; Wright, P. J.; O'Brien, P.; Motevalli, M. J. Mater. Chem. 1993, 3, 1203. (f) Turnipseed, S. B.; Barkley, R. M.; Sievers, R. E. Inorg. Chem. 1991, 30, 1164.

(11) (a) Schulz, D. L.; Hinds, B. J.; Neumayer, D. A.; Stern, C. L.; Marks, T. J. Chem. Mater. 1993, 5, 1605. (b) Watson, I. M.; Atwood, M. P.; Haq, S. Supercond. Sci. Technol. 1994, 7, 672. (c) Neumayer, D. A.; Belot, J. A.; Feezel, R. L.; Reedy, C.; Stern, C. L.; Marks, T. J.; Liable-Sands, L. M.; Rheingold, A. L. Inorg. Chem. 1998, 37, 5625 .

(12) Mehrotra, R. C.; Singh, A.; Sogani, S. Chem. Soc. Rev. 1994, 23:33, 215. (13) (a) Labrize, F.; Hubert-Pfalzgraf, L. G.; Vaissermann, J.; Knobler, C. B. Polyhedron 1996, 15, 577. (b) Borup, B.; Huffman, J. C.; Caulton, K. G. J. Organomet. Chem. 1997, 536-537, 109. (c) Borup, B.; Streib, W. E.; Caulton, K. G. Inorg. Chem. 1997, 36, 5058. (d) Rees, W. S.; Caballero, C. R.; Hesse, W. Angew. Chem. 1992, 104, 786. (e) Love, C. P.; Torardi, C. C.; Page, C. J. Inorg. Chem. 1992, 31, 1784. Labrize, F.; Hubert-Pfaltzgraf, L. G.; Daran, J.-C.; Halut, S. J. Chem. Soc., Chem. Comm. 1993, 1556. (f) Miele, P.; Foulon, J. D.; Hovnanian, N.; Cot, L. J. Chem. Soc., Chem. Comm. 1993, 29. (g) Sauer, N. S.; Garcia, E.; Salazar, K. V.; Ryan, R. R.; Martin, J. A. J. Am. Chem. Soc. 1990, 112, 1524. (h) Bidell, W.; Shklover, V.; Berke, H. Inorg. Chem. 1992, 31, 5561. 
Scheme 1. Synthesis of Ligands $\mathbf{L}$ and $\mathbf{L}^{\prime}$ Followed up by the Successive Coordination of Two Different Metal Ions, $\mathbf{M}^{1}$ and $\mathbf{M}^{2}$, Respectively (Anions of Metal Salts Not Shown)

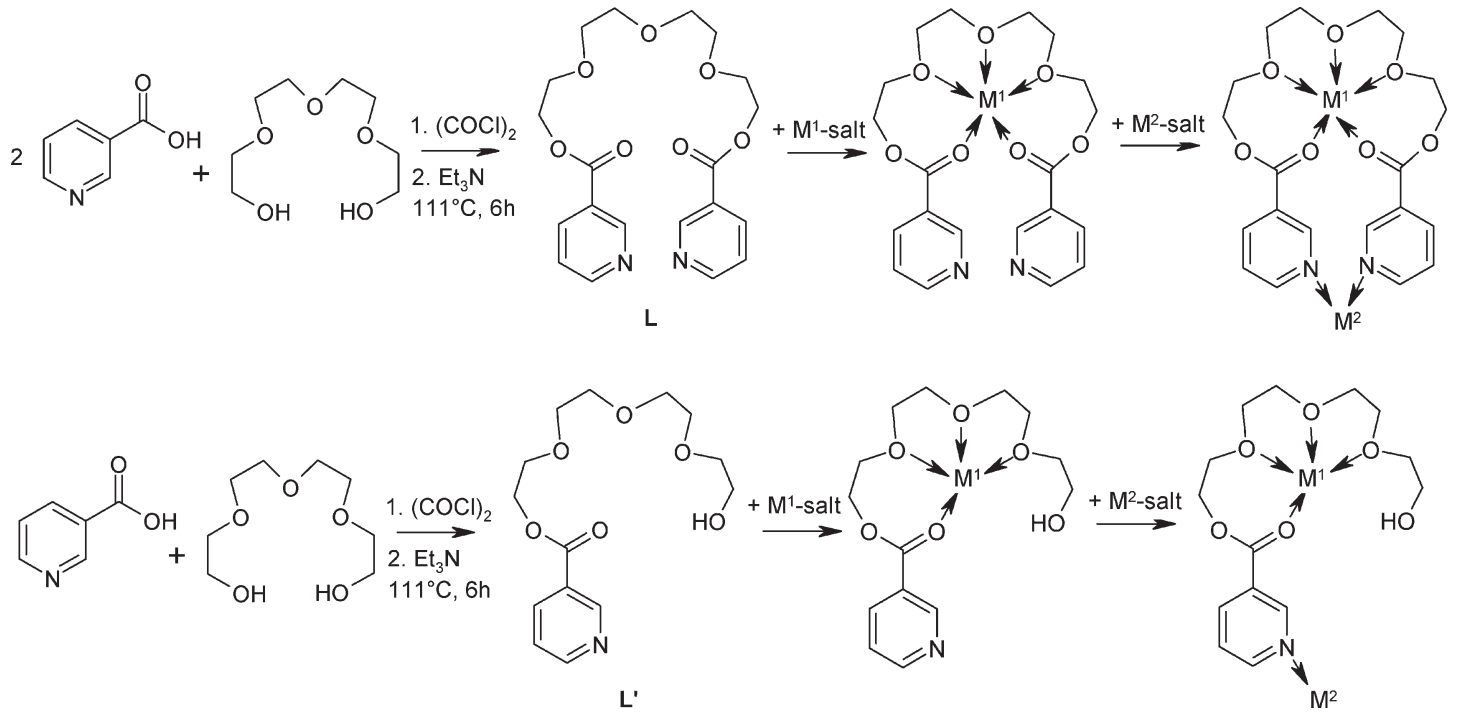

and $\left[\mathrm{BaCu}(\mathrm{O} t \mathrm{Bu})_{2}(\text { thd })_{2}\right]_{n}$ (Hthd $=2,2,6,6$,-tetramethyl-3, 5-heptanedione) were isolated, but they possess high sublimation temperatures, even when transformed into the THF adducts, and show a tendency to decompose. ${ }^{13 \mathrm{a}}$ There have also been several approaches to synthesize heterometallic copper(II)-alkaline-earth metal complexes, for example, calcium-copper complexes with 1,3-bis-(dimethylamino)2-propanolato (bdmap) and trifluoroacetato ligands. ${ }^{14}$ In these compounds, however, the coordination of the ligand(s) to the metal ion is uncontrolled and not selective, so that the final compound cannot be predicted. To our knowledge, no conceptual approach has been made to use tailored ligands adapted to the specific properties of the metal ions. Therefore, the design of mixed-metal species is of considerable interest in relation to their potential application as precursors for (MO-)CVD or sol-gel techniques.

We propose to design single-source precursors based on functionalized polyether molecules, since these molecules are usually stable, adaptable and flexible, and easy to handle. Thus, we developed the ligands $\mathbf{L}$ and $\mathbf{L}^{\prime}$, which allow coordination to different metal ion types via different ligating atoms (Scheme 1). In the first part of this paper, the coordination behavior of $\mathbf{L}$ is studied. With alkaline earth metal ions such as calcium, the ligand $\mathbf{L}$ is supposed to wrap around the metal ion, yielding a complex in which the nitrogen atoms are expected to be oriented so as to accommodate another metal ion, for example, a transition metal ion. In the second part, we study the coordination of $\mathbf{L}$ to the transition metal ion alone, before combining both metal ions within one single compound in a last step. With ligand $\mathbf{L}^{\prime}$, we will then show that this concept works as well, presenting another heterometallic species obtained as well via the selective binding of $\mathbf{L}^{\prime}$ to two different metal ions.

Thus, we here report the design and synthesis of a novel ligand, its homometallic compounds obtained with calcium and copper ions, and finally a new mixed-metal calcium-copper precursor for mixed-metal oxides. We confirm the principle of selective binding of different metal ions with a second ligand. We will also show that the concept of this

(14) Breeze, S. R.; Wang, S. Inorg. Chem. 1994, 33, 5113. precursor works by presenting first decomposition experiments of the heterometallic compounds, which show that mixed-metal oxides can be obtained.

\section{Results and Discussion}

Design, Synthesis, and Crystal Structure of the Ligand $L$ $\left[\mathrm{C}_{\mathbf{2 0}} \mathbf{H}_{\mathbf{2 4}} \mathbf{O}_{\mathbf{7}} \mathbf{N}_{2}\right]$. We chose the ligand $\mathrm{O}, \mathrm{O}^{\prime}$-bisnicotinic acid tetraethylene glycol $(\mathbf{L})$ for its potential to coordinate to two different metal ions for the generation of bimetallic species (Scheme 1). In our group, ligands of the type polyethylene glycol with two nicotinic acid or isonicotinic acid functions in terminal positions are well-studied. ${ }^{15-17}$ Due to its quite long polyether chain, $\mathbf{L}$ can adopt different conformations. ${ }^{18}$ We therefore wanted to learn about the most stable one in the solid state.

The synthesis of $\mathbf{L}$ (Scheme 1 and Figure 1) consists of a simple reaction between nicotinic acid chloride and tetraethylene glycol, heated together in a ratio of 2:1. Needlelike crystals grow from the crude product in a solution of dichloromethane/hexane after a few days. L crystallizes in the orthorhombic space group $F d d 2$. The unit cell contains half a molecule, which is completed by symmetry through O4 (Figure 1a). L displays a "W"-shape conformation, with the ether groups at the ethylene units presenting a gauche conformation. Within a molecule of $\mathbf{L}$, the two pyridine rings lie in mean planes, which form an angle of $76.1(1)^{\circ}$ to each other. From C3 to its symmetry equivalent $\mathrm{C}^{\prime}$, the molecule $\mathbf{L}$ has a length of ca. $17.7 \AA$ (without $\mathrm{H}$ atoms).

The molecules of $\mathbf{L}$ pack in a fishbone arrangement along the $z$ plane, with $\mathrm{H}$-bonding between $\mathrm{C} 10 \cdots \mathrm{N} 1$, $\mathrm{C} 8 \cdots \mathrm{O} 1$, and $\mathrm{C} 3 \cdots \mathrm{O} 2$ and corresponding symmetry equivalents of neighboring molecules. Such layers are

(15) Fromm, K. M.; Robin, A. Y. Coord. Chem. Rev. 2006, 250.

(16) Robin, A. Y.; Sagué, J. L.; Fromm, K. M. CrystEngComm 2006, 8, 403.

(17) Robin, A. Y.; Fromm, K. M.; Goesmann, H.; Bernardinelli, G. CrystEngComm 2003, 5, 405.

(18) (a) Jouaiti, A.; Hosseini, M. W.; Kyritsakas, N. Chem. Commun. 2003, 472. (b) Robin, A. Y.; Sagué, J. L.; Fromm, K. M. CrystEng Comm 2006, 8 , 403. 
a)

b)
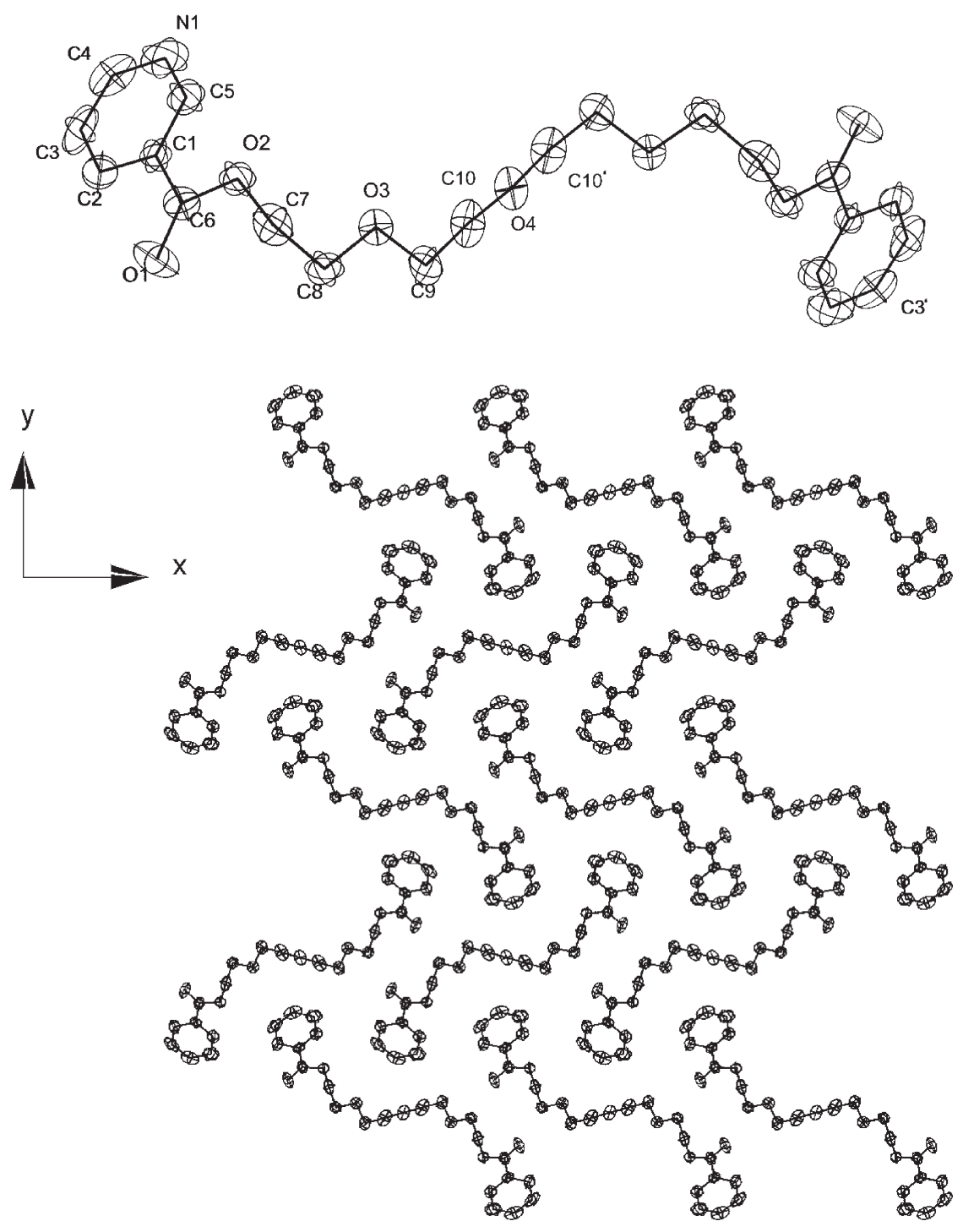

Figure 1. (a) Single molecule of $\mathbf{L}$ and numbering. (b) Fishbone arrangement along the $z$ axis of $\mathbf{L}$ (hydrogen atoms are omitted for clarity).

stacked on top of each other with a shortest distance of 3.58(1) A (distance measured between both mean pyridine planes), allowing thus $\pi$ interactions between the pyridine rings.

Under the same reaction conditions, but at a molecular ratio of 1:1 nicotinic acid chloride to tetraethylene glycol, the reaction takes place on only one side of the glycol, yielding the asymmetric ligand $\mathbf{L}^{\prime}$ (Scheme 1). This ligand presents itself as oil and was therefore characterized via NMR. The idea of synthesizing $\mathbf{L}^{\prime}$ is to have less steric hindrance in order to be able to complex larger metal ions such as barium.

In order to learn about the flexibility of the ligand and its capacity to adapt to different metal ions, we investigated first the coordination of $\mathbf{L}$ to calcium ions, then to copper ions, and finally explored the possibility of formation of a mixed-metal compound.

Coordination of $\mathrm{L}$ to Calcium Ions: The Compounds $\left[\mathrm{Ca}(\mathrm{L})\left(\mathrm{H}_{2} \mathrm{O}\right)_{3}\right] \mathbf{I}_{2}(\mathbf{1})$ and $\left[\mathrm{Ca}(\mathrm{L})\left(\mathrm{H}_{2} \mathrm{O}\right)_{3}\right] \mathbf{I}_{2} \cdot\left(\mathrm{CHCl}_{3}\right)_{2}$ (2) Containing Isomeric Complex Cations. From the reaction of $\mathbf{L}$ with $\mathrm{CaI}_{2}$, two different forms of $\left[\mathrm{Ca}(\mathbf{L})\left(\mathrm{H}_{2} \mathrm{O}\right)_{3}\right] \mathrm{I}_{2}$ are obtained, one crystallizing with chloroform (2) as a cocrystallizing solvent molecule, the other without a solvent molecule (1). Instead of one being the solvated form of the other, the two structures differ significantly from each other, as described in the following.

Crystal Structure of $\left[\mathrm{Ca}(\mathrm{L})\left(\mathrm{H}_{2} \mathrm{O}\right)_{3}\right]_{\mathbf{2}}, \mathbf{1}$. When $\mathrm{CaI}_{2}$ is reacted with $\mathbf{L}$ in chloroform, a dark yellow solution is obtained after filtration of the residue. After slow evaporation at room temperature (RT), yellow rhombic crystals of $\mathbf{1}$ are obtained. Compound $\mathbf{1}$ crystallizes in the centrosymmetric, monoclinic space group $P 2_{1} / c$. The unit cell consists of a complete molecule of $\mathbf{1}$, as shown in Figure 2. As expected in Scheme 1, the ligand $\mathbf{L}$ wraps around the calcium ion, changing its conformation compared to its "W" structure and coordinating with the four oxygen atoms $\mathrm{O} 3, \mathrm{O} 4, \mathrm{O} 5$, and $\mathrm{O} 7$ to the cation with distances between 2.35(1) and 2.49(9) $\AA$. The coordination sphere around the cation is completed by three water molecules, O8, O9, and $\mathrm{O} 10$ (average $\mathrm{Ca}-\mathrm{O}$ of $2.34 \AA$ ), to yield a distorted pentagonal-bipyramidal arrangement of $\mathrm{O}$ atoms, where $\mathrm{O} 9$ and $\mathrm{O} 10$ occupy the axial positions 


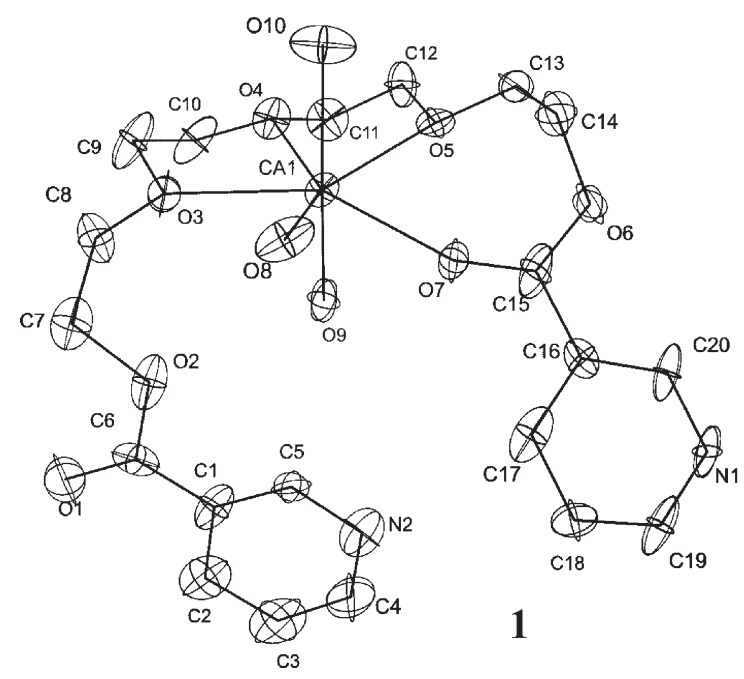

Figure 2. Cationic complex and numbering of $\mathbf{1}$ (hydrogen atoms and iodide atoms are omitted for clarity).

and $\mathrm{O} 8$ as well as the above-mentioned oxygen atoms of $\mathbf{L}$ are the equatorial ones. The anions I1 and I2 are $\mathrm{H}$-bonded to the water molecules $\mathrm{O} 8$ and $\mathrm{O} 10$ and molecules O9 and O10, respectively, as well as their symmetry equivalents (average I $1 \cdots \mathrm{H}$ of $2.76(3) \AA$ and $\mathrm{I} 2 \cdots \mathrm{H}$ of $2.85(1) \AA$ ), leading to a $\mathrm{H}$-bonded, overall three-dimensional network in the solid state.

The surprising feature within this molecule of $\mathbf{1}$ is the asymmetric coordination of the carbonyl $\mathrm{O}$ atoms of $\mathbf{L}$, one pointing inward ("in"), coordinating the calcium ion with $\mathrm{O} 7$, the other being oriented outward ("out") with O1 pointing away from the cation. In the solid state, the "in" nicotinic acid moiety of one molecule packs with an "out" nicotinic acid of a neighbor molecule at a distance of $3.29 \AA$ (measured between the pyridine planes of two neighbored molecules), indicating $\pi-\pi$ stacking. The second ring at the molecule does not interact with any other molecule, so that a dimer is formed. As mentioned before, these dimers are then linked via $\mathrm{H}$ bonds between water molecules $\mathrm{O} 8, \mathrm{O} 9$, and $\mathrm{O} 10$ and iodide anions into a three-dimensional network.

Crystal Structure of $\left[\mathrm{Ca}(\mathrm{L})\left(\mathrm{H}_{2} \mathrm{O}\right)_{3}\right] \mathrm{I}_{2} \cdot\left(\mathrm{CHCl}_{3}\right)_{2} 2$. A different isomer of the calcium complex is obtained when the crystallization is carried out at a lower temperature $\left(-24^{\circ} \mathrm{C}\right)$. Then, 2 crystallizes in the monoclinic space group $P 2_{1} / n$, its unit cell consisting of a complete calcium complex as in $\mathbf{1}$, but with two additional chloroform molecules. Similar to $\mathbf{1}$, the calcium ion loses its two iodide anions from its direct coordination sphere. In contrast to $\mathbf{1}$, however, the ligand coordinates symmetrically to the cation using both carbonyl oxygen atoms $\mathrm{O} 1$ and $\mathrm{O} 7$ (with a $\mathrm{Ca}-\mathrm{O}$ distance of 2.38(8) and 2.39(1) $\AA$, respectively) and three polyether oxygen atoms, $\mathrm{O} 3, \mathrm{O} 4$, and $\mathrm{O} 5$ (average $\mathrm{Ca}-\mathrm{O}$ distances 2.54(5) $\AA$ ). Together with three water molecules, O8, O9, and O10 (average $\mathrm{Ca}-\mathrm{O}$ distances $2.41(4) \AA$ ), this gives a higher coordination number of eight for the cation in $\mathbf{2}$ than that in $\mathbf{1}$ (Figure 3, Scheme 2). The calcium ion thus has a square antiprismatic coordination sphere. A comparison of our data with calcium complexes involving simple polyethylene ligands and an identical coordination number shows that our distances are in the same range as the ones in the literature examples. ${ }^{19-22}$ The cationic complex forms dimers (Figure 3b) via hydrogen bonds between the water molecule $\mathrm{O} 8$ of one molecule and the nitrogen atoms N1 and $\mathrm{N} 2$ of the second. Offset $\pi$ stacking between the pairs of pyridine rings of each cationic unit is observed at the short distance of $3.34 \mathrm{~A}$ between $\mathrm{C} 5$ of one molecule and C16 of the neighbor pyridine group.

The anion I1 forms hydrogen bonds to the water molecules $\mathrm{O} 9$ and $\mathrm{O} 10$ of one complex and $\mathrm{O} 10$ of a neighbor molecule (average $\mathrm{I} 1-\mathrm{H}$ of $2.95 \AA$ ). On the other hand, I2 forms four hydrogen bonds: to C4 and C19 and to the hydrogen atoms of both chloroform molecules (C21 and C22) with an average distance of $2.95 \AA$. This hydrogen bonding leads to a network in which the dimers form channels, and the chloroform molecules are located between these rows of channels.

For comparison, the most important bond lengths and angles for $\mathbf{1}$ and $\mathbf{2}$ are listed in Table 1. A neat difference between the seven-coordinated compound $\mathbf{1}$ and the eight-coordinated $\mathbf{2}$ is reflected in the $\mathrm{Ca}-\mathrm{O}$ bond lengths. It can be seen that the $\mathrm{Ca}-\mathrm{O}$ bonds of $\mathbf{1}$ are on average shorter than the ones in compound $\mathbf{2}$. This can be explained by the fact that the calcium ion needs to pull more electron density from the oxygen atoms when only seven oxygen atoms surround it, than in the preferred eight-coordination. In order to estimate which complex, the one in $\mathbf{1}$ or the one in $\mathbf{2}$, is more stable, bond valence sums $^{23}$ were calculated for the calcium cation in each case. For the eight-coordinated complex 2, a value of 2.16 is obtained, which is very close to the formal expected oxidation state of +2 of the $\mathrm{Ca}^{2+}$ ion $(8 \%$ deviation from the assumed valence state). For compound $\mathbf{1}$, it is slightly higher (2.28), which shows that the $\mathrm{Ca}$ ion is more "intensely" coordinated. This difference of coordination and thus ligand conformation has an impact on other structural features of the two complexes. Thus, the pyridine rings within $\mathbf{L}$ of the asymmetric compound $\mathbf{1}$ form an angle of $40.6(6)^{\circ}$, while in compound $\mathbf{2}$, the pyridine units are almost coplanar $\left(9.6(2)^{\circ}\right)$. This difference can be explained by the missing coordination of the second carbonyl group in $\mathbf{1}$. In compound $\mathbf{2}$, the plane containing the calcium ion and the polyether oxygen atoms forms an angle of $78.2(3)^{\circ}$ with the plane formed by the nicotinic acid units. The same plane, $\mathrm{Ca}-\mathrm{O} 3-\mathrm{O} 4-\mathrm{O} 5$, in compound 1 forms an angle of $77.7(6)^{\circ}$ with one of the nicotinic groups containing $\mathrm{C} 6, \mathrm{O} 1$, and $\mathrm{N} 1$, and the

(19) (a) Wei, Y. Y.; Tinant, B.; Declercq, J. P.; Van Meerssche, M. Acta Crystallogr., Sect. C 1987, C43(1), 86. (b) Wei, Y. Y.; Tinant, B.; Declercq, J. P.; Van Meerssche, M.; Dale, J. Acta Crystallogr., Sect. C 1987, C43(6), 1076. (c) Wei, Y. Y.; Tinant, B.; Declercq, J. P.; Van Meerssche, M.; Dale, J. Acta Crystallogr., Sect. C 1987, C43(7), 1270. (d) Wei, Y. Y.; Tinant, B.; Declercq, J. P.; Van Meerssche, M.; Dale, J. Acta Crystallogr., Sect. C 1987, C43(7), 1279. (e) Wei, Y. Y.; Tinant, B.; Declercq, J. P.; Van Meerssche, M.; Dale, J. Acta Crystallogr., Sect. C 1987, C43(6), 1080. (f) Wei, Y. Y.; Tinant, B.; Declercq, J. P.; Van Meerssche, M.; Dale, J. Acta Crystallogr., Sect. C 1987, C43(7), 1274. (20) Junk, P. C. J. Chem. Crystallogr. 1999, 29(9), 997.

(21) Rogers, R. D; Bond, A. H. Acta Crystallogr., Sect. C 1992, C48(10), 1782

(22) Fromm, K. M.; Goesmann, H.; Bernardinelli, G. Polyhedron 2000, 19(15), 1783

(23) (a) Kanowitzer, S. M.; Palenik, G. J. Inorg. Chem. 1998, 37, 2086. (b) Wood, R. M.; Abboud, K. A.; Palenik, R. C. Inorg. Chem. 2000, 39, 2065. (c) Wills, A. S. VaList. Program available from www.ccp14.ac.uk (accessed September 2009). (d) Brown, I. D.; Altermatt, D. Acta Crystallogr. 1985, B41, $244-47$. 
a)

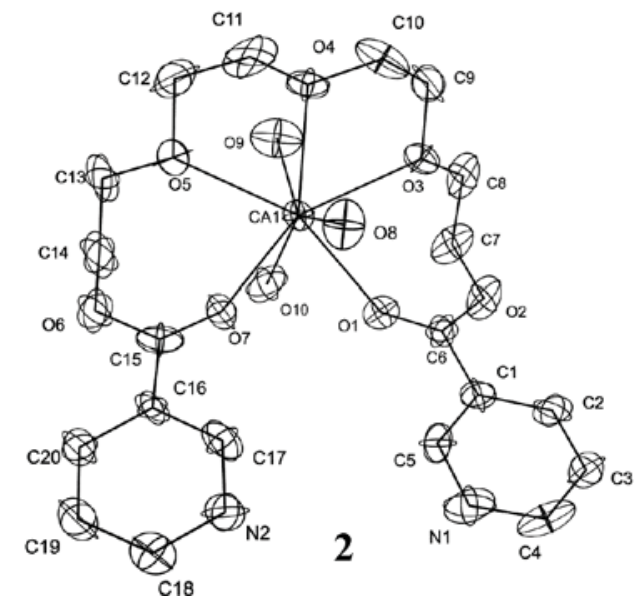

b)

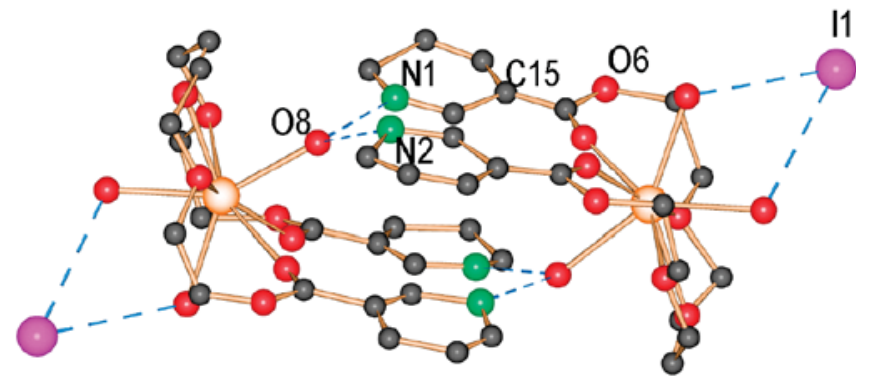

Figure 3. (a) Cationic complex and numbering of 2. (b) Packing of dimers of $\mathbf{2}$ and involved $\mathrm{H}$ bonding (some $\mathrm{I}$ atoms, all $\mathrm{H}$ atoms, as well as $\mathrm{CHCl}_{3}$ molecules are omitted for clarity).

Scheme 2. Schematic Representation of the Coordination of $\mathbf{L}$ to the Calcium Ion in $\mathbf{1}$ (left) and $\mathbf{2}$ (right) and the Three Rotations Needed to Transform 1 into 2
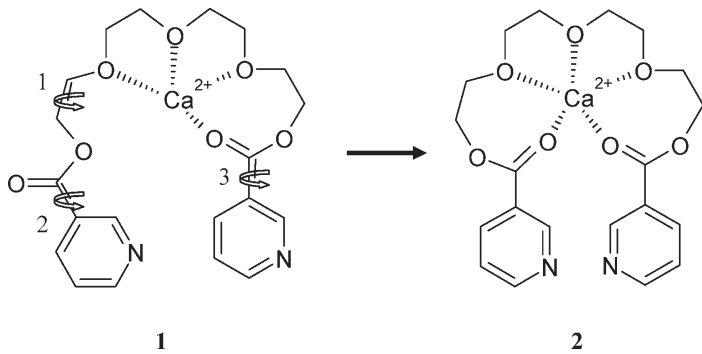

Table 1. Selected Bond Lengths and Angles for Compounds 1, 2, and 4

\begin{tabular}{lccl}
\hline & $\mathbf{1}$ & $\mathbf{2}$ & \multicolumn{1}{c}{$\mathbf{4}$} \\
\hline $\mathrm{O} 1-\mathrm{Ca}$ & & $2.39(1)$ & $2.41(7)$ \\
$\mathrm{O} 3-\mathrm{Ca}$ & 2.424 & $2.56(9)$ & $2.58(3)$ \\
$\mathrm{O} 4-\mathrm{Ca}$ & 2.394 & $2.46(4)$ & $2.50(2)$ \\
$\mathrm{O} 5-\mathrm{Ca}$ & $2.55(1)$ & $2.60(9)$ & $2.58(3)$ \\
O7-Ca & $2.35(2)$ & $2.39(8)$ & $2.41(7)$ \\
O8-Ca & $2.35(1)$ & $2.38(4)$ & O5-Ca 2.395 \\
O9-Ca & $2.34(9)$ & $2.48(7)$ & O6-Ca 2.365 \\
O10-Ca & $2.33(1)$ & $2.45(2)$ & \\
$\mathrm{Ca}-\mathrm{I} 4$ & & & $3.68(1)$ \\
$\mathrm{C} 1-\mathrm{C} 6-\mathrm{O} 1$ & $124.4(6)$ & $123.9(7)$ & $124.2(1)$ \\
$\mathrm{C} 1-\mathrm{C} 6-\mathrm{O} 2$ & $113.8(2)$ & $112.8(2)$ & 110.30 \\
C16-C15-O6 & $113.7(1)$ & $115.7(2)$ & \\
$\mathrm{C} 16-\mathrm{C} 15-\mathrm{O} 7$ & $124.0(5)$ & $122.9(8)$ &
\end{tabular}

other nicotinic group $\mathrm{C} 15-\mathrm{O} 7-\mathrm{N} 2$ forming an angle of 43.7(9) ${ }^{\circ}$. Concerning the ligand conformations in $\mathbf{1}$ and $\mathbf{2}$, at least three rotations around bonds within $\mathbf{L}$ have to be performed to come to approximately the same ligand arrangement in both. As shown in Scheme 2, rotation number 1 would allow for the carbonyl group to turn inward, rendering its coordination to the cation possible. Then, however, rotation number 2 has to occur simultaneously in order to keep the nitrogen atom of the pyridine ring oriented inward as well. On the other side of the ligand, rotation number 3 will also lead to an inward turn of the pyridine nitrogen atom. Previous theoretical calculations on the flexibility of a similar ligand, but with a short ethylene bridge as a spacer, have shown that the different ligand conformations are energetically very close to each other and can easily be reached at room temperature. ${ }^{24}$ In solution, the ligand $\mathbf{L}$ alone should indeed be able to adopt many possible conformations. Upon coordination to calcium ions, the ligand has to adopt a general "U" shape. This conformation of $\mathbf{L}$, especially the one in compound $\mathbf{2}$, seems to be a prerequisite for the coordination of a second metal ion type at the $\mathrm{N}$-donor atoms of $\mathbf{L}$, as shown in Scheme 1, as will be shown later.

When the synthesis of $\mathbf{1}$ and $\mathbf{2}$ is repeated several times, isomer $\mathbf{1}$ could be obtained more easily at RT with different crystallization techniques, while compound $\mathbf{2}$ can be only obtained at a low temperature $\left(-24^{\circ} \mathrm{C}\right)$. Furthermore, the crystals of $\mathbf{2}$ tend to melt rapidly at room temperature and in inert oil. This indicates that $\mathbf{1}$ seems to be the more stable compound at RT. The instability of $\mathbf{2}$ can presumably be explained by solvent loss when the crystal is taken out of the mother liquor. Even though nature tends toward symmetry (here, diminishing of the molecular dipole moment in $\mathbf{2}$ compared to 1), the stability of the first isomer can also be explained according to thermodynamic aspects. One is the formation of two seven-member rings in compound $\mathbf{2}$, compared to one in $\mathbf{1}$. This leads to a higher ring strain in compound $\mathbf{2}$. Furthermore, the entropy gained in $\mathbf{1}$ by the possible rotation around the $\mathrm{C} 6-\mathrm{O} 1$ bond certainly also contributes to the stability of $\mathbf{1}$ versus $\mathbf{2}$.

A tool other than X-ray analysis used to differentiate both isomers in the solid state is IR spectroscopy, where the carbonyl band can be inspected; compound 1 shows two carbonyl bands at $1724 \mathrm{~cm}^{-1}$ and at $1697 \mathrm{~cm}^{-1}$, the first band for the coordinated $\mathrm{C}=\mathrm{O}$ and the lower band for the free carbonyl groups. Compound $\mathbf{2}$ exhibits, as expected, only one band at $1735 \mathrm{~cm}^{-1}$. In solution, however, 1 cannot be differentiated from $\mathbf{2}$, which indicates a fast on-and-off-coordination of $\mathrm{O} 1$ and $\mathrm{O} 7$ in both compounds. To evidence this, both complexes $\mathbf{1}$ and $\mathbf{2}$ were dissolved in acetonitrile and also in $\mathrm{CDCl}_{3}$ and measured in ${ }^{1} \mathrm{H}$ NMR, where no obvious difference could be seen. NMR at variable temperatures $\left(-30\right.$ to $\left.+30{ }^{\circ} \mathrm{C}\right)$

(24) (a) Robin, A. Y.; Meuwly, M.; Fromm, K. M.; Goesmann, H.; Bernardinelli, G. CrystEngComm 2004, 6(60), 336. 


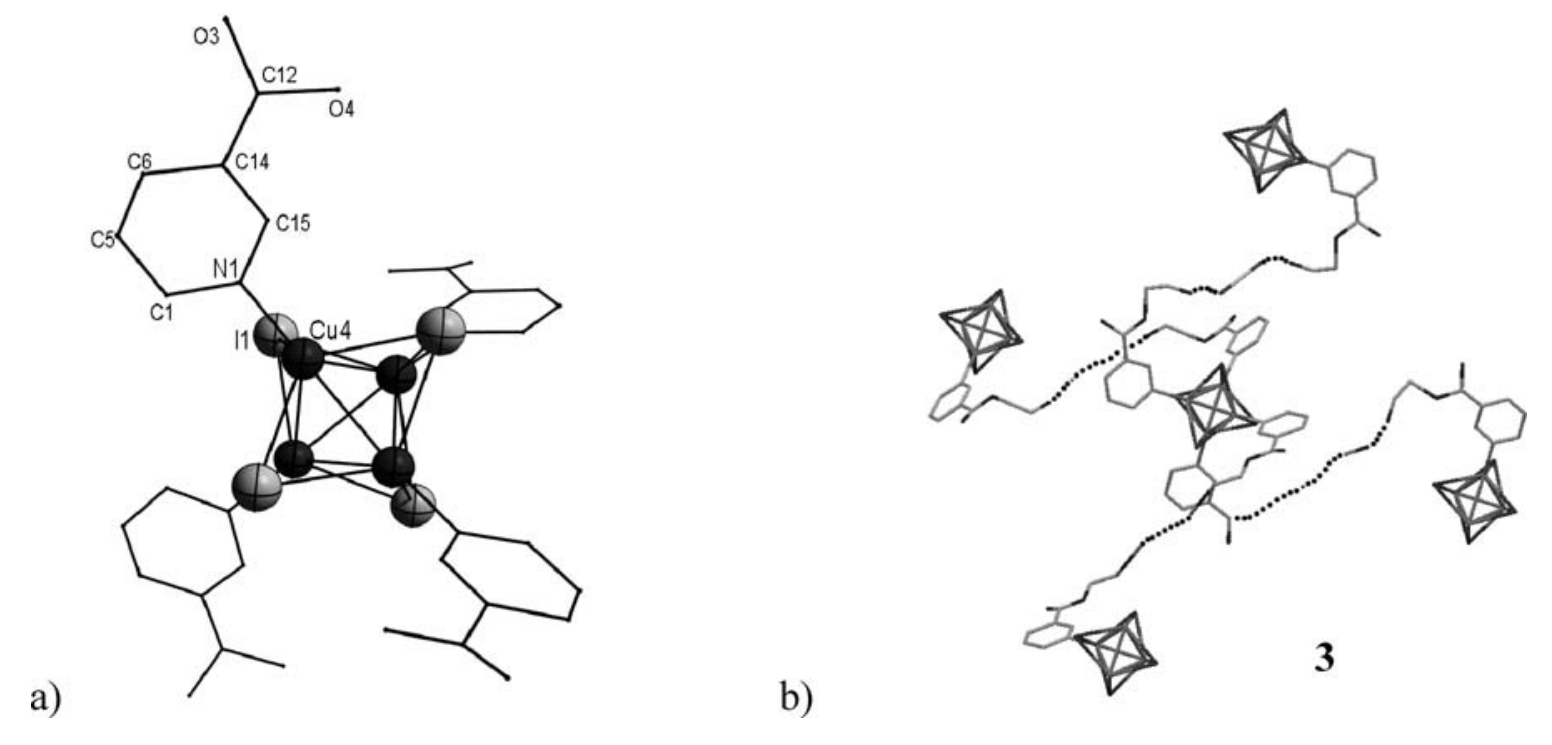

Figure 4. (a) $\mathrm{Cu}_{4} \mathrm{I}_{4}$ core with the nicotinic units of 3. (b) Approximative extrapolation of the tetraethylene glycol chains between the core units.

also did not show significant changes. The solutions were also then measured by FT-IR. The double band of compound $\mathbf{1}$ collapsed to an average, large band around $1720 \mathrm{~cm}^{-1}$. Also, the sharp carbonyl band of compound 2 disappeared. Even though the solid starting materials show a neat difference in IR, both solutions have nearly identical spectra, and it is no longer possible to identify both compounds.

Having shown that ligand $\mathbf{L}$ uses the oxygen donor atoms to coordinate to alkaline earth metal ions, we next tested its coordination behavior toward copper ions.

Coordination of $\mathbf{L}$ to Copper Ions: Crystal Structure of $\left\{\left[\mathbf{C u}_{\mathbf{4}} \mathbf{I}_{\mathbf{4}}(\mathbf{L})_{2}\right]\left(\mathrm{H}_{2} \mathrm{O}\right)_{2}\right\}_{\mathrm{n}}$ (3). Reacting $\mathrm{CuI}$ with $\mathbf{L}$ in chloroform, we could obtain the metal organic framework (MOF) $\left\{\left[\mathrm{Cu}_{4} \mathrm{I}_{4}(\mathrm{~L})_{2}\right]\left(\mathrm{H}_{2} \mathrm{O}\right)_{2}\right\}_{n}, 3$, in a yield of ca. $50 \%$. As the ligand $\mathbf{L}$ is highly flexible in the spacer part, strong disorder of the flexible and noncoordinating polyether chains was observed, and we were not able to solve this part of the structure of $\mathbf{3}$ completely. However, from possible split positions of the polyether moiety, it can be concluded that the structure is unambiguously the MOF described below, with analyses confirming the formation of the MOF.

Compound $\mathbf{3}$ crystallizes in the centrosymmetric, monoclinic space group $I 2 / a$. The asymmetric unit of $\mathbf{3}$ consists of a $\mathrm{Cu}_{4} \mathrm{I}_{4}$ cluster to which four different halves of ligand molecules $\mathbf{L}$ are coordinated, binding to the copper ions via the nitrogen atom, respectively. For some of the ligands, the carbon atoms attached to the nicotinic acid groups can be found and attributed in the solid-state structure, but the further polyether chains are strongly disordered. The core of the structure is shown in Figure 4. $\mathrm{The} \mathrm{Cu}-\mathrm{Cu}$ distances are between 2.64(6)- and 2.66(8)$\AA$-long. In the literature, many $\mathrm{Cu}_{4} \mathrm{I}_{4}$ clusters could be found, with $\mathrm{Cu}-\mathrm{Cu}$ distances of $2.56-2.75 \AA$, showing therefore that 3 fits well into this class of compounds. ${ }^{25}$ Since the polyether chains were strongly disordered, the question arose of whether $\mathbf{3}$ is a molecular compound in which two nicotinic moieties of the same cluster unit are

(25) (a) Zhao, Z. G.; Zhang, J.; Wu, X. Y. CrystEngComm 2008, 10, 273. (b) Bi, M.; Li, G.; Hua, J.; Liu, X. CrystEngComm 2007, 9, 984. connected with each other, yielding a molecular cluster with two ligands in "U" shape, or whether a polymeric network is formed, in which the ligands all connect to neighbor clusters in a stretched conformation (Figure 4). To find this out, we tried to describe the structure with split positions for the atoms along the polyether chains. With this treatment, we could clearly see that the cluster units are linked to one another forming a three-dimensional, tetrahedral porous network. In the split positions, additional $\mathrm{H}$-bonded water molecules seem to complicate the pattern. The findings were therefore confirmed by other analytical methods. Thus, thermogravimetric analysis under nitrogen shows a first small mass loss at $160^{\circ} \mathrm{C}$ $(-2.1 \%)$, very likely due to a loss of intercalated solvent, best fitting to two water molecules (calculated 1.99\%). A further decomposition at $292{ }^{\circ} \mathrm{C}$ indicates the decomposition of organic material $(43 \%$ measured versus $49 \%$ expected-this is likely due to partial decomposition and carbonate formation). The last peak $(-33.3 \%)$ at $590{ }^{\circ} \mathrm{C}$ corresponds best to the loss of the four iodide atoms of the $\mathrm{Cu}_{4} \mathrm{I}_{4}$ units (calculated $32 \%$ ), leading to remaining copper oxide and carbonate, as indicated by the IR spectrum of the residue.

The yellow compound $\mathbf{3}$ shows a strong green fluorescence under UV light and was therefore investigated for luminescence properties. UV-vis spectroscopy shows an absorption maximum of $\mathbf{3}$ at $265 \mathrm{~nm}$ and, when excited at this wavelength, a strong emission band at $537 \mathrm{~nm}$. This luminescence property of multinuclear copper clusters, especially $\mathrm{Cu}_{4} \mathrm{I}_{4}$ units, is known and has been studied in the literature. ${ }^{26}$ As the same reaction for obtaining 3 was repeated in an apolar solvent (heptane, hexane), a slightly yellow amorphous precipitate, $\mathbf{3}^{\prime}$, formed immediately. Under UV light, the precipitate shows an orange fluorescence, induced probably by slight structural changes, possibly due to different or no intercalated solvent molecules in $\mathbf{3}^{\prime}$ compared to $\mathbf{3}^{26 \mathrm{a}}$ When excited at a wavelength

(26) (a) De Angelis, F.; Fantacci, S.; Sgamellotti, A.; Cariati, El.; Ugo, R.; Ford, P. C. Inorg. Chem. 2006, 45, 10576. (b) Hu, S.; Tong, M. L. Dalton Trans 2005, 1165. (c) Ryu, C. K.; Vitale, M.; Ford, P. C. Inorg. Chem. 1993, 32, 869. (d) Zhou, J.; Bian, G.-Q.; Dai, J.; Zhang, Y.; Zhu, Q.-Y.; Lu, W. Inorg. Chem. 2006, 45,8486 . 
Table 2. Crystallographic Tables for $\mathrm{L}, \mathbf{1}, \mathbf{2}, \mathbf{3}, \mathbf{4}$, and $\mathbf{5}$

\begin{tabular}{|c|c|c|c|c|c|c|}
\hline & $\mathbf{L}$ & 1 & 2 & 3 & 4 & 5 \\
\hline formula sum & $\mathrm{C}_{20} \mathrm{H}_{24} \mathrm{~N}_{2} \mathrm{O}_{7}$ & $\begin{array}{c}\mathrm{C}_{20} \mathrm{H}_{30} \mathrm{CaI}_{2} \\
\mathrm{~N}_{2} \mathrm{O}_{10}\end{array}$ & $\begin{array}{l}\mathrm{C}_{22} \mathrm{H}_{32} \mathrm{Ca} \\
\mathrm{Cl}_{6} \mathrm{I}_{2} \mathrm{~N}_{2} \mathrm{O}_{10}\end{array}$ & $\begin{array}{c}\mathrm{C}_{40} \mathrm{H}_{52} \mathrm{Cu}_{4} \\
\mathrm{I}_{4} \mathrm{~N}_{4} \mathrm{O}_{14}\end{array}$ & $\begin{array}{l}\mathrm{C}_{20} \mathrm{H}_{28} \mathrm{Ca} \\
\mathrm{Cu}_{3} \mathrm{I}_{5} \mathrm{~N}_{2} \mathrm{O}_{9}\end{array}$ & $\begin{array}{r}\mathrm{C}_{62} \mathrm{H}_{90} \mathrm{Ba}_{2} \mathrm{Cl}_{6} \\
\mathrm{Cu}_{3} \mathrm{I}_{7} \mathrm{~N}_{4} \mathrm{O}_{24}\end{array}$ \\
\hline fw & 404.42 & 752.35 & 991.11 & 1574.67 & 1305.69 & 2841.75 \\
\hline space group & $F d d 2$ & $P 2(1) / c$ & $P 2(1) / n$ & $I 2 / a$ & Pnma & $I 2 / a$ \\
\hline$T,{ }^{\circ} \mathrm{C}$ & $200(2)$ & $200(2)$ & $200(2)$ & $200(2)$ & $200(2)$ & $200(2)$ \\
\hline$a, \AA$ & $24.445(5)$ & $11.368(2)$ & $16.306(3)$ & $12.308(3)$ & $13.023(3)$ & $22.733(5)$ \\
\hline$b, \AA$ & $36.787(7)$ & $17.383(4)$ & $10.524(2)$ & $37.403(8)$ & $14.858(3)$ & $10.792(2)$ \\
\hline$c, \AA$ & $4.5773(9)$ & $14.505(3)$ & $22.164(4)$ & $12.509(3)$ & 17.961(4) & $43.094(9)$ \\
\hline$\alpha, \operatorname{deg}$ & 90 & 90 & 90 & 90 & 90 & 90 \\
\hline$\beta, \operatorname{deg}$ & 90 & $93.26(3)$ & $91.43(3)$ & $97.57(3)$ & 90 & $104.06(3)$ \\
\hline$\gamma, \mathrm{deg}$ & 90 & 90 & 90 & 90 & 90 & 90 \\
\hline$V, \mathrm{~A}^{3}$ & $4116.2(14)$ & $2861.8(10)$ & $3802(13)$ & $5709(2)$ & $3475.4(13)$ & $10256(4)$ \\
\hline$\rho_{\text {calcd }}, \mathrm{g} \mathrm{cm}^{-3}$ & 1.305 & 1.746 & 1.731 & 0.935 & 2.495 & 1.982 \\
\hline$\mu, \mathrm{cm}^{-1}$ & 0.99 & 2.427 & 2.257 & 1.847 & 6.452 & 3.850 \\
\hline$Z$ & 4 & 4 & 4 & 2 & 4 & 8 \\
\hline$R$ & 0.0552 & 0.0727 & 0.0825 & 0.1162 & 0.0652 & 0.0897 \\
\hline$w R_{2}$ & 0.1292 & 0.1552 & 0.1907 & 0.3230 & 0.1180 & 0.2206 \\
\hline completeness, $\theta$ & $97.5 \%$ & $80.5 \%$ & $88.6 \%$ & $99.5 \%$ & $95.9 \%$ & $74.1 \%$ \\
\hline GoF & 1.094 & 1.158 & 1.156 & 1.015 & 1.040 & 1.056 \\
\hline $\begin{array}{l}\text { reflns } \\
\text { unique }\end{array}$ & $4254 / 1269$ & $6438 / 3140$ & $14362 / 4941$ & $26929 / 3823$ & $13643 / 2361$ & $17243 / 6456$ \\
\hline$F(000)$ & 1712 & 1480 & 1944 & 2640 & 2424 & 5848 \\
\hline
\end{tabular}

of $366 \mathrm{~nm}$, the solid sample in heptanes shows an emission band at $598 \mathrm{~nm}$. TGA analysis of the freshly prepared compound $3^{\prime}$ did not show a small weight loss at $160^{\circ}$ as it did for 3, but it has otherwise the same shape and decomposition behavior. After evaporation of the solvent and exposition of $\mathbf{3}^{\prime}$ to the air, the green fluorescence of $\mathbf{3}$ recovers. TGA analysis of this rehydrated sample shows again a small solvent loss around $160^{\circ}$ as in $\mathbf{3}$, indicating a solvatochromism and supporting the idea that water might be the solvent included in the cavities of $\mathbf{3}$.

In order to further confirm our theory that $\mathbf{3}$ is a MOF, a powder sample has been used to determine the porosity via $\mathrm{N}_{2}$ absorption experiments. Compound 3 turns out to possess a Brunauer-Emmett-Teller (BET) surface of $3.2 \mathrm{~m}^{2} / \mathrm{g}$ as well as an average pore diameter of $267.8 \AA$. This indicates a good porosity for such a material. In comparison with other MOFs for hydrogen or carbon dioxide storage ${ }^{27}$, however, compound $\mathbf{3}$ has a small surface area $\left(3.2 \mathrm{~m}^{2} / \mathrm{g}\right.$ vs $\left.181-4500 \mathrm{~m}^{2} / \mathrm{g}\right)$ but a big pore diameter $(267.8$ vs $3.6-17 \AA$ ), the latter of which is probably responsible for the fast $\mathrm{N}_{2}$ uptake and release. Indeed, it is possible to observe a hysteresis in the $\mathrm{N}_{2}$ isotherms, showing that the pores can be filled and emptied many times without losing this absorption and desorption potential (see the Supporting Information). The crystal structure, admitting stretched out ligands between the cluster units, confirms the huge dimension of these pores in $\mathbf{3}$.

The experiment with $\mathrm{CuI}$ has shown that, if a metal cation only interacts with the nitrogen atoms of $\mathbf{L}$, the ligand does remain in a rather stretched out conformation, similar to the one found in the solid-state structure of $\mathbf{L}$ alone. These first three structures, $\mathbf{1 - 3}$, confirm that ligand $\mathbf{L}$ binds well to $\mathrm{Cu}(\mathrm{I})$ ions with the nitrogen donors only, and to the alkaline earth metal ions via the oxygen atoms, so we attempted next to synthesize a mixed-metal

(27) (a) Rowsell, J. L. C.; Yaghi, O. M. J. Am. Chem. Soc. 2006, 128, 1304. (b) Millward, A. R.; Yaghi, O. M. J. Am. Chem. Soc. 2005, 127, 17998. (c) Rosi, N. L.; Kim, J.; Eddaoudi, M.; Chen, B.; O'Keeffe, M.; Yaghi, O. M. J. Am. Chem. Soc. 2005, 127, 1504. (d) Sudik, A. C.; Côté, A. P.; Wong-Foy, A. G.; O'Keeffe, M.; Yaghi, O. M. Angew. Chem., Int. Ed. 2006, 45, 2528.

compound containing both metal ion types. Crystallographic data for $\mathbf{L}, \mathbf{1}, \mathbf{2}$, and $\mathbf{3}$ as well as for compounds $\mathbf{4}$ and $\mathbf{5}$ are collected in Table 2 .

Coordination of $\mathrm{L}$ to Calcium and Copper Ions: Crystal Structure of $\left[\mathbf{C a C u}_{3}(\mathbf{L}) \mathrm{I}_{5}\left(\mathrm{H}_{2} \mathrm{O}\right)_{2}\right]_{\mathrm{n}}$, 4. Upon the slow addition of solid $\mathrm{CuI}$ (powder) into a mixture of $\mathrm{CaI}_{2}$ and $\mathbf{L}$ in chloroform, the mixed metal, one-dimensional polymeric compound $\left[\mathrm{CaCu}_{3}(\mathrm{~L}) \mathrm{I}_{5}\left(\mathrm{H}_{2} \mathrm{O}\right)_{2}\right]_{n}$, 4, was obtained. Its synthesis takes place in a two-step, one-pot reaction: First, the ligand $\mathbf{L}$ is allowed to react with the calcium salt for $12 \mathrm{~h}$, and only then is the copper salt added. If the reaction is carried out in the inverse order, compound $\mathbf{3}$ is obtained as the main product. Compound 4 crystallizes in the orthorhombic space group Pnma. A monomeric unit of $\mathbf{4}$ consists of a $(\mathrm{CaL})$ complex similar to that in $\mathbf{2}$, but with two water molecules and one iodide anion connected to the cation instead of three water molecules in 2. Furthermore, the nitrogen atoms of this complex coordinate now to two copper cations, $\mathrm{Cu} 1$ and its symmetry equivalent $\mathrm{Cu} 1^{\prime}$. Together with $\mathrm{Cu} 2$, these three copper ions form a triangular cluster unit which is $\mu_{3}$-capped on one face by I1. Each of the three edges of the $\mathrm{Cu}$ triangle is bridged by one iodide each (I2, I2', and I3), pointing down the opposite face relative to $\mathrm{I} 1$. While I2 and $\mathrm{I} 2^{\prime}$ adopt a simple bridging mode between pairs of copper ions $\left(\mathrm{Cu} 1-\mathrm{Cu} 2\right.$ and $\left.\mathrm{Cu}^{\prime}-\mathrm{Cu} 2\right)$, I3, which is bridging $\mathrm{Cu} 1-\mathrm{Cu}^{\prime}$, acts as connecting unit to $\mathrm{Cu} 2$ of the neighbor cluster unit. Each $\mathrm{Cu} 1\left(\mathrm{Cu}^{\prime}\right)$ is tetrahedrally coordinated by one nitrogen atom $\mathrm{N} 1\left(\mathrm{~N} 1^{\prime}\right)$ and three iodide anions, I1, I2, and $\mathrm{I} 3$ (I1, I2', I3), while $\mathrm{Cu} 2$ is coordinated by four iodide ions, I1, I2, I2', and $\mathrm{I}^{\prime}{ }^{\prime}$. Several CuI clusters and oligomers are known, ${ }^{28}$ but the arrangement in $\mathbf{4}$ is a unique one-dimensional chain motif, based mainly on copper and iodide ions, and to which, in a syndiotactic fashion, the calcium complexes are connected (Figure 5).

(28) (a) Hartl, H.; Mahdjour-Hassan-Abadi, F. Angew. Chem. 1994, 106 , 1929-1931. (b) Adam, D.; Herrschaft, B .; Hartl, H. Z. Naturforsch. 1991, 46b, 738-746. (c) Cheng, J. K.; Yao, Y. G.; Zhang, J.; Li, Z. J. J. Am. Chem. Soc. 2004, 126(25), 7796-7797. 


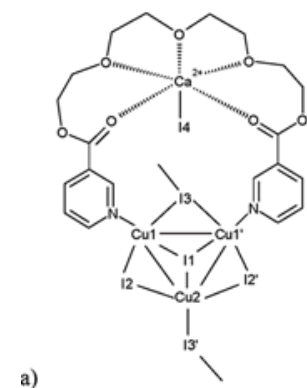

a)
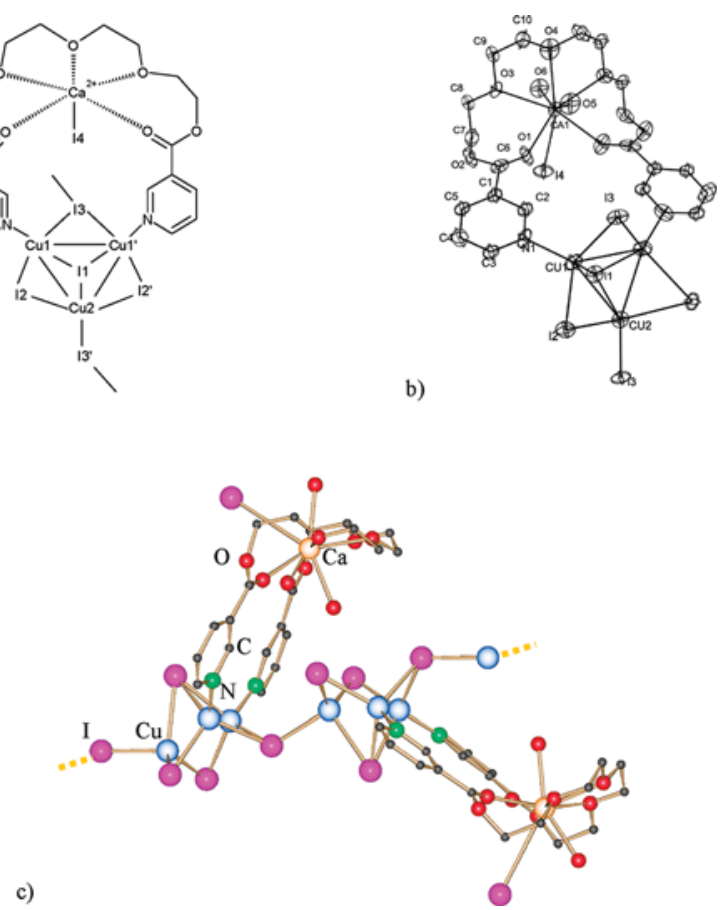

Figure 5. (a) Schematic representation and numbering of $4\left(\mathrm{H}_{2} \mathrm{O}\right.$ omitted for clarity). (b) Monomeric unit of $\mathbf{4}$ and numbering. (c) 1D polymer chain of $\mathbf{4}$ (hydrogen atoms are omitted for clarity).

The ligand thus adopts a loop shape and uses its oxygen atoms $\mathrm{O} 1, \mathrm{O} 3, \mathrm{O} 4, \mathrm{O}^{\prime}$, and $\mathrm{O}^{\prime}$ to bind to the calcium cation, leading to the symmetric binding mode as observed in 2. This latter seems to be favored here due to coordination of the $\mathrm{N}$ atoms to the copper ions. In contrast to $\mathbf{2}$, the calcium cation completes its coordination number of eight with two water molecules $\mathrm{O} 5$ and O6 and one iodide I4. Similar to $\mathbf{1}, \mathrm{H}$ bonding between O5 and $\mathrm{I} 2$ of a neighbor unit at a distance of $2.34 \mathrm{~A}$ is observed. The pyridine rings are coplanar due to symmetry. The bond lengths $\mathrm{Ca}-\mathrm{O}$ in $\mathbf{4}$ are longer on average than the ones in $\mathbf{2}$, which is very likely induced by the binding of an anion in the form of I4. For bond valence sum calculation, a value of 2.07 is obtained, which is very close to the formal expected oxidation state of +2 of the $\mathrm{Ca}^{2+}$ ion. A crystallographic mirror plane passes through the calcium ion Ca1 $(x, 0.25$, $y$; (e)), as well as the coordinated water molecules $\mathrm{O} 5$ and $\mathrm{O} 6$, the calcium-bonded iodide $\mathrm{I} 1, \mathrm{I} 3$, and $\mathrm{Cu} 2$ (all $x$, $0.25, y ;(\mathrm{e}))$.

As compared to Scheme 1, where we expected a 1:1 complex between the metal ions $\mathrm{M}^{1}$ and $\mathrm{M}^{2}$, compound 4 shows a ratio of $1: 3$ between calcium and copper ions. The distance between the two pyridyl nitrogen atoms in compound 2 is 4.28(2)- $\AA$-long and would thus allow in principle one copper ion to be coordinated. With typical $\mathrm{Cu}-\mathrm{N}$ distances ${ }^{26}$ of around $2 \AA$, this would however lead to an unsuitable $\mathrm{N}-\mathrm{Cu}-\mathrm{N}$ angle for a tetrahedral coordination sphere. Indeed, the two nitrogen atoms of $\mathbf{L}$ in 2 form $\mathrm{H}$ bonds to one water ligand coordinated to a second calcium complex with distances $\mathrm{N}-\mathrm{O}$ of ca. 2.7-2.8 $\AA$ and an angle $\mathrm{N}-\mathrm{O}-\mathrm{N}$ of ca. $105^{\circ}$. A shorter distance, for example, $2 \AA$ for a possible $\mathrm{Cu}-\mathrm{N}$, would lead to a wider angle. In compound $\mathbf{4}$, the $\mathrm{N}-\mathrm{N}$ distance within one ligand is, by 5.52(6) $\AA$, widened compared to 2 , allowing the ligand to "comfortably" coordinate two copper ions instead of one metal ion.

Attempts at obtaining a mixed-metal barium-copper compound (as a precursor for, for example, YBCO) using $\mathbf{L}$ were unsuccessful so far. This might be due to the fact that barium cations require a higher coordination number, and the one ligand molecule of $\mathbf{L}$ cannot satisfy this, even in the presence of water molecules. We therefore proposed to use the asymmetric ligand $\mathbf{L}^{\prime}$ for the coordination of barium cations. Similarly as for compound 4, a heterometallic species is easily obtained, this time in a one-step reaction, as shown in the next paragraph.

Coordination of $\mathbf{L}^{\prime}$ to Barium and Copper Ions: Crystal Structure of $\left\{\left[\mathrm{Ba}_{2} \mathrm{Cu}_{3}\left(\mathbf{L}^{\prime}\right)_{4} \mathrm{I}_{7}\right] \cdot\left(\mathrm{CH}_{2} \mathrm{Cl}_{2}\right)_{3}\right\}_{\mathrm{n}}, 5$. A clear yellow solution forms upon the addition of $\mathbf{L}^{\prime}$ to a suspension of $\mathrm{BaI}_{2}$ and $\mathrm{CuI}$ in $\mathrm{CH}_{2} \mathrm{Cl}_{2}$, from which single crystals and a precipitate are obtained after slow evaporation. Crystals as well as the precipitate turn out to consist of the heterometallic barium-copper complex $\left\{\left[\mathrm{Ba}_{2} \mathrm{Cu}_{3}\left(\mathbf{L}^{\prime}\right)_{4} \mathrm{I}_{7}\right] \cdot\left(\mathrm{CH}_{2} \mathrm{Cl}_{2}\right)_{3}\right\}_{n}, \mathbf{5}$. In contrast to $\mathbf{4}$, this barium-copper compound can be obtained in a onepot reaction. This is possible because the ligand $\mathbf{L}^{\prime}$ is asymmetric and cannot form a coordination polymer network with $\mathrm{CuI}$ as in compound 3. Compound $\mathbf{5}$ crystallizes in the orthorhombic space group $I 2 / a$ with half a molecule in the asymmetric unit. One molecule consists of two barium cations, three copper cations, four $\mathbf{L}^{\prime}$ ligands, and five iodide counterions (Figure 6). Two iodide anions as well as solvent molecules are not directly connected to the cationic entity. Each barium cation is coordinated by two ligand molecules, which bind to the alkaline earth cation via the 10 oxygen donor atoms and in a head-to-head fashion. The $\mathrm{Ba}-\mathrm{O}$ bonds are comprised between 2.672(6) and 2.995(2) $\AA$, similar as reported in the literature for barium glycol complexes (between $2.61 \AA$ and $3.25 \AA$ ), ${ }^{28}$ and lead to a bond valence sum for the alkaline earth metal cation of $2.36(18 \%$ deviation from the assumed valence state).

One of these two ligands binds to a copper ion $\mathrm{Cu} 1$ via the pyridyl moiety. This copper ion (special position 0 , $y, 0.25(\mathrm{~g}))$ is connected to a second, symmetry equivalent barium complex, again coordinated by one of the $\mathrm{N}$ atoms. $\mathrm{Cu} 1$ is furthermore part of $\mathrm{C}_{3} \mathrm{I}_{5}{ }^{2-}$ cluster unit, in which three copper ions $\left(\mathrm{Cu} 1, \mathrm{Cu} 2\right.$, and $\left.\mathrm{Cu} 2^{\prime}\right)$ are bridged by three iodide ions, I2, I2', and I3, adopting a "twistane" conformation of the six-membered $\mathrm{Cu}_{3} \mathrm{I}_{3}$ ring. $\mathrm{Cu} 2$ and its symmetry equivalent each carry a terminal iodide ligand, I4, to complete their coordination number to three (angle sum of $355^{\circ}$ ), while $\mathrm{Cu} 1$ has a coordination number of four (tetrahedral). To the best of our knowledge, this type of isolated $\mathrm{Cu}_{3} \mathrm{I}_{5}{ }^{2-}$ core is unknown in the literature. Remarkably, within the cationic complex of $\mathbf{5}$, the correct stoichiometric ratio between the metal ions $\mathrm{Ba} / \mathrm{Cu}=2: 3$ is realized, which is needed to produce the superconducting oxide $\mathrm{Y}_{1} \mathrm{Ba}_{2} \mathrm{Cu}_{3} \mathrm{O}_{7}$.

One of the two Ba-coordinating ligands does not bind to a second metal ion, and its uncoordinated pyridyl moiety is thus able to form $\mathrm{H}$ bonds with one $\mathrm{HO}$ group of a neighbor $\left[\mathrm{Ba}_{2}\left(\mathbf{L}^{\prime}\right)_{4} \mathrm{Cu}_{3} \mathrm{I}_{5}\right]^{2+}$ unit (Figure 7). A ladder-type structure is obtained in which 
a)

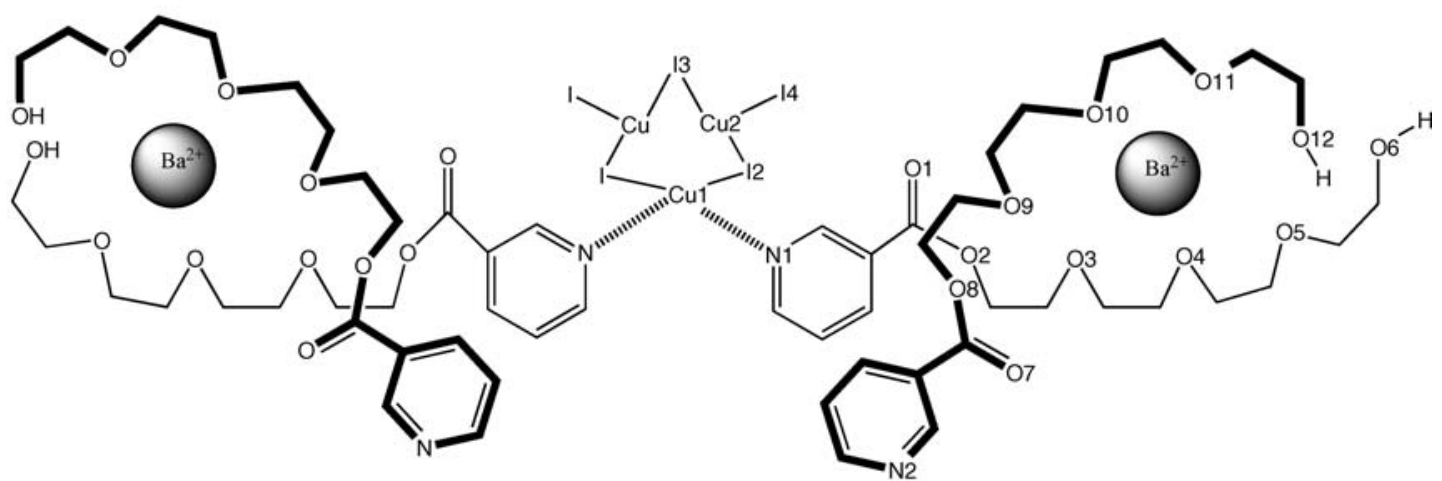

b)

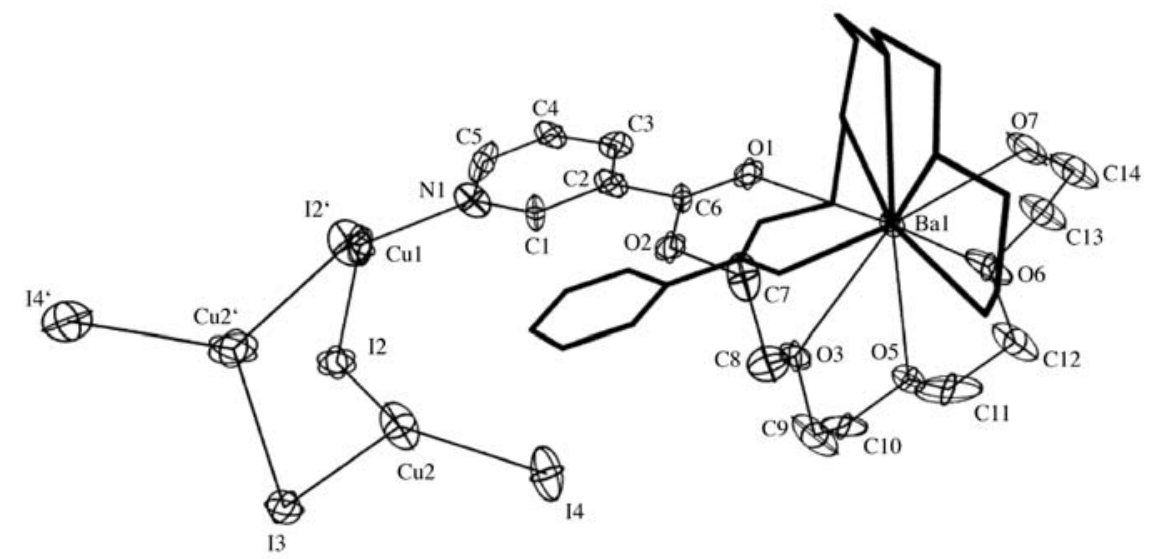

c)

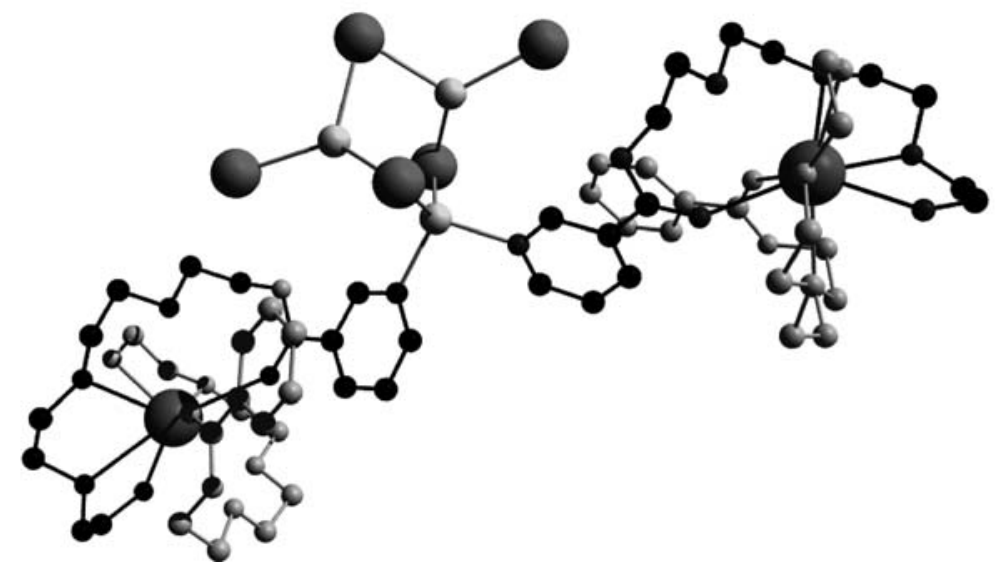

Figure 6. (a) Scheme of the cationic complex in 5. (b) ORTEP plot of one half cationic complex of 5 with atom numbering. (c) Cationic complex of 5.

the complexes are arranged in ribbons. The terminal iodide ions of the $\mathrm{Cu}_{3} \mathrm{I}_{5}$ unit, I4 and its symmetry equivalent, are $\mathrm{H}$-bonded to one $\mathrm{CH}_{2} \mathrm{Cl}_{2}$ molecule each. The lone iodide, $\mathrm{I} 1$, and its symmetry equivalent are involved in weak $\mathrm{H}$ bonding $(\mathrm{C} 14 \cdots \mathrm{I} 1 \cdots \mathrm{O} 12)$, connecting the ribbons into a three-dimensional network. The residual $\mathrm{CH}_{2} \mathrm{Cl}_{2}$ molecules have only weak interactions to $\mathrm{I} 4$, respectively $\mathrm{I} 1$, and to carbon atoms

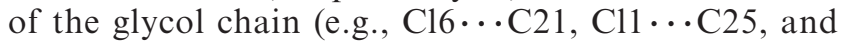
$\mathrm{Cl} 15 \cdots \mathrm{C} 11)$.
In the ${ }^{1} \mathrm{H}$ NMR spectrum, the signals of the protons near the nitrogen atom of the nicotinic acid moiety are broadened and also shifted by $0.5 \mathrm{ppm}$ to lower field values, indicating the copper coordination also in solution. This coordination is confirmed by a bathochromic shift of the UV spectrum by ca. $100 \mathrm{~nm}$ compared to $\mathbf{L}^{\prime}$ alone.

Decomposition Experiments. As the goal of the work is to obtain compounds which can be used as precursors, for example, for $\mathrm{YBCO}$ or $\mathrm{BSCCO}$, decomposition 


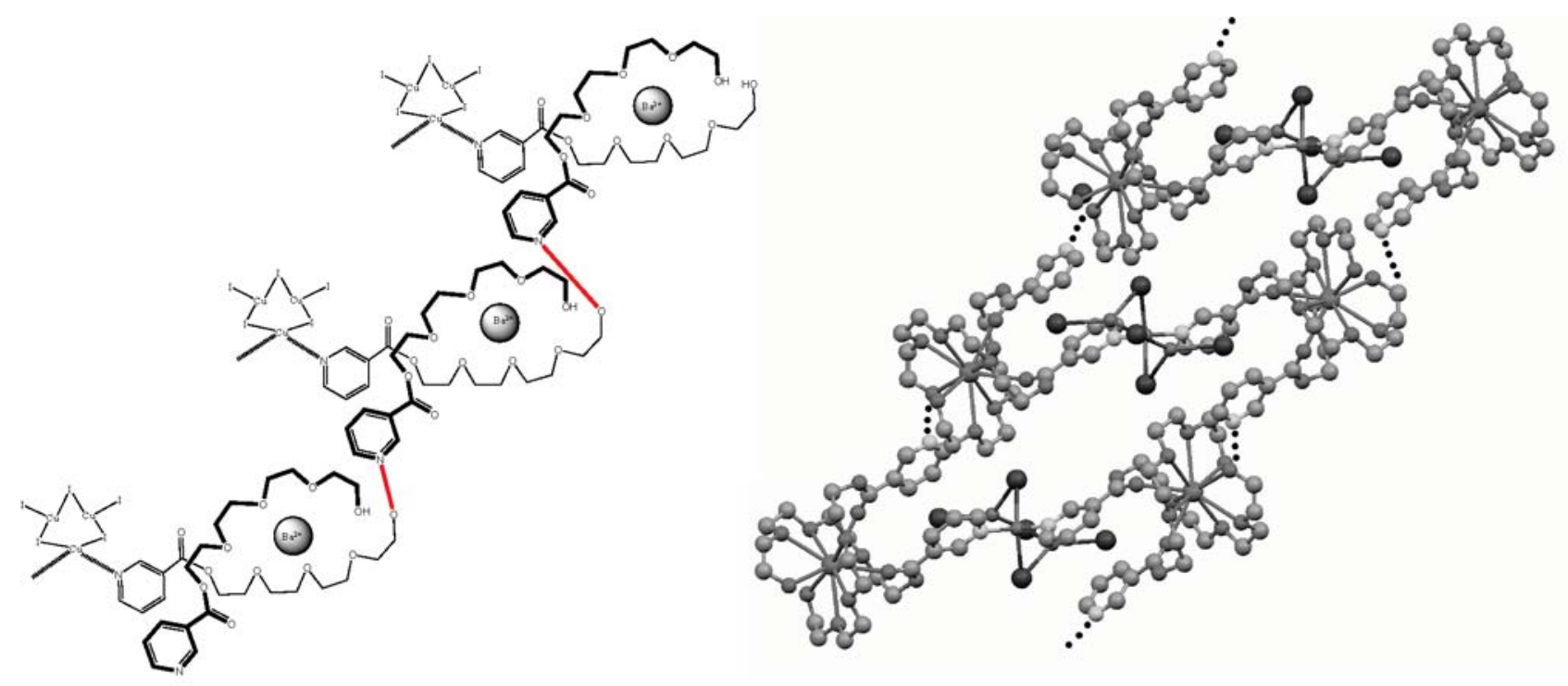

a)

b)

Figure 7. (a) Scheme of the $\mathrm{H}$ bonding between the complexes in 5. (b) Polymer ribbon of compound 5.

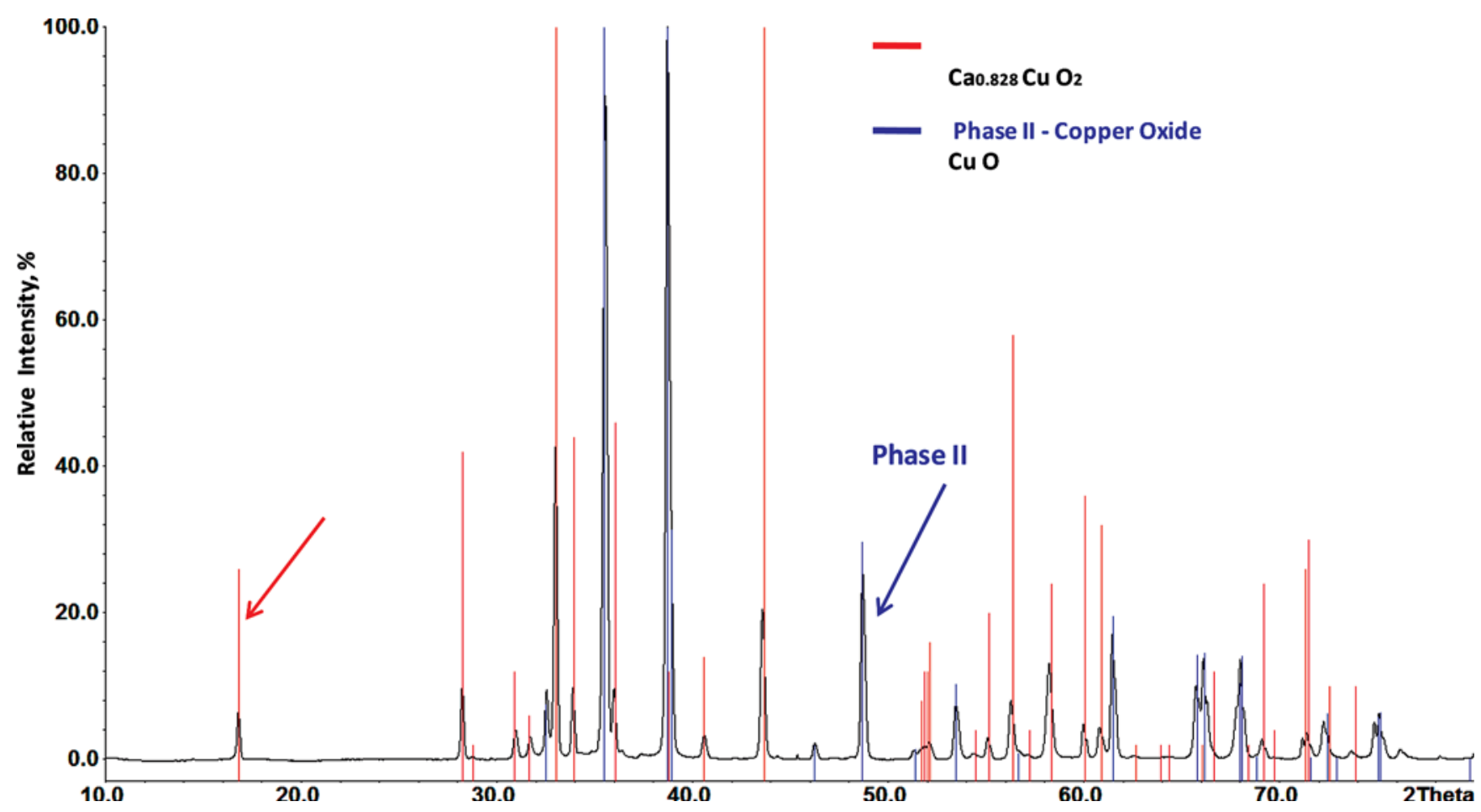

Figure 8. Powder X-ray pattern of a sample of $\mathbf{4}$ heated in the air over a Bunsen flame. Phase I (red) corresponds to the mixed metal oxide, while phase II (blue) is $\mathrm{CuO}$.

experiments were carried out in order to check whether compounds $\mathbf{4}$ and $\mathbf{5}$ are able to form the parent metal oxide with a composition of $1: 3 \mathrm{Ca} / \mathrm{Cu}$ and $2: 3 \mathrm{Ba} / \mathrm{Cu}$, respectively. For compound 4, the TGA measurement (Supporting Information) showed a one-step decomposition process around $290{ }^{\circ} \mathrm{C}$, associated with a strong exothermic peak corresponding to the combustion of the organic material. The total weight loss was $84.4 \%$, which corresponds quite well to the mass of the organic material and the five iodide atoms $(82.4 \%)$. A sample of
4 was then heated in the air to $>290{ }^{\circ} \mathrm{C}$ until decomposition, and the obtained black powder was analyzed by IR and XRD. In the FT-IR data of the black powder, some very weak bands around $1600 \mathrm{~cm}^{-1}$ could be observed, showing the presence of remaining organic material, for example, carbonate. Elemental analysis of the metal ion contents reveals an approximate stoichiometry of 1:2.8. The powder was polycrystalline and could be analyzed using XRD (Figure 8), showing two phases. 
The two metal oxides were identified as $\mathrm{CuO}$ and the mixed-metal oxide $\mathrm{Ca}_{0.828} \mathrm{CuO}_{2}$, the latter being discussed as a residual oxide in the synthesis of superconductors. ${ }^{30}$ Furthermore, this compound presents a metastable oxide in the $\mathrm{Ca}-\mathrm{Cu}-\mathrm{O}$ phase diagram. ${ }^{30 \mathrm{~b}}$ In comparison, compound $\mathbf{1}$ decomposes only to yield $\mathrm{CaCO}_{3}$ up to $700{ }^{\circ} \mathrm{C}$, above which both carbonate and $\mathrm{CaO}$ are formed.

Compound 5 decomposes also upon heating to yield a mixture of metal oxides, namely, $\mathrm{CuO}$ and $\mathrm{Ba}_{88} \mathrm{Cu}_{97} \mathrm{O}_{220}$ (see the Supporting Information). ${ }^{30 \mathrm{c}}$ The latter belongs to the group of $\mathrm{BaCuO}_{2+x}$ oxides which are studied in the context of their magnetic properties. Among other barium copper oxides, Hodorowicz et al. found $\mathrm{BaCuO}_{2}$ in the $\mathrm{Y}_{2} \mathrm{O}_{3}-\mathrm{BaCO}_{3}-\mathrm{CuO}$ system, and Zhang et al. ${ }^{6}$ reported that $\mathrm{BaCuO}_{2}$ and $\mathrm{Ba}_{2} \mathrm{CuO}_{3}$ can be made in the $\mathrm{CuO}-\mathrm{BaO}$ system under a partial pressure of $0.21 \mathrm{~atm}$ of $\mathrm{O}_{2}{ }^{30 \mathrm{~d}} \mathrm{Ba}_{2} \mathrm{Cu}_{3} \mathrm{O}_{5}$, the expected oxide from compound $\mathbf{5}$, has been obtained by solid-phase reaction, ${ }^{30 \mathrm{e}}$ but singlecrystal material could not be obtained.

Thus, with our method, it is possible to obtain such (i) metastable phases and (ii) possibly also new oxide phases which are difficult to isolate otherwise. In the powder diffraction pattern, all of the peaks can be assigned to these two oxides, which is an important result, as we can thus exclude the formation of carbonates upon combustion in the air. This proves that our approach can indeed lead to interesting oxide materials in the field of superconductors.

\section{Conclusions}

In this paper, it was shown how a multitopic ligand $\mathbf{L}$ was designed and used for the site-selective binding of an alkaline earth and a transition metal ion. It was proven that this selectivity exists when each type of metal ion is reacted alone with the ligand. Upon coordination of $\mathbf{L}$ to copper ions, the ligand uses only its $\mathrm{N}$ donors to build a porous MOF, $\mathbf{3}$, which reversibly takes up and releases gas molecules such as nitrogen. As in its free form, the ligand adopts a stretched out conformation. In the case of the calcium complex, two forms of coordination by the ligand are observed, $\mathbf{1}$ and $\mathbf{2}$, both of which occur solely via the oxygen atoms of $\mathbf{L}$, which is found in an all-gauche conformation. In case of stepwise addition of the calcium salt to the ligand, followed by the copper salt, one specific ligand conformation is then clearly preferred, yielding finally the mixed-metal compound $\mathbf{4}$, which can be used as a precursor for metastable mixed oxides. Compound $\mathbf{5}$ confirms the use of such a ligand type for selectively binding different metal ions and forming heterometallic compounds. As fascinating "side effects", we were also able to identify new $\mathrm{Cu}_{x} \mathrm{I}_{y}{ }^{n-}$ units or polymer chains, which were previously unknown.

It was shown that the heterometallic precursors $\mathbf{4}$ and $\mathbf{5}$ yielded oxides, while the homometallic precursor 1 forms carbonate. Even if the oxides formed upon decomposition of

(30) (a) Badica, P.; Iyo, A.; Aldica, G.; Kito, H.; Crisan, A.; Tanaka, Y. Supercond. Sci. Technol. 2004, 17, 430. (b) Mathews, T.; Hajra, J. P.; Jacob, K. T. Chem. Mater. 1993, 5, 1669. (c) Villars, P.; Cenzual, K. Pearson's Crystal Database; Crystal Impact: Bonn, Germany, 2008. (c) Guskos, N. J. Solid State Chem. 1995, 119, 50. (d) Shibata, S.; Unoki, H.; Kuroda, K.; Koshizuka, N. J. Mater. Sci. Lett. 1997, 16, 1295. (e) Maiorosa, A. F.; Mudretsova, S. N.; Kovba, M. L.; Monaenkova, A. S.; Popova, A. A. Physica C 1993, 218, 137. $\mathbf{4}$ and $\mathbf{5}$ are mixed oxides, this ligand class will allow a rational strategy to synthesize stoichiometrically exact mixed-metal compounds and the mixed-metal oxides via a facile synthetic route, without using air-sensitive materials or processes. Other combinations of metal ions with $\mathbf{L}$ and its derivatives such as $\mathbf{L}^{\prime}$, as well as ligands allowing the selective binding of more than two metal ions, and their decomposition into oxides, are currently under investigation in our laboratory.

\section{Experimental Section}

Materials and Methods. All reagents were purchased from chemical companies and used without further purification. For single-crystal measurements, a Stoe IPDS II theta, equipped with monochromated Mo K $\alpha$ radiation $(0.71073 \AA)$, was used. Single crystals of $\mathbf{L}$ and $\mathbf{1 - 4}$ were picked under the microscope, placed in inert oil, and measured at $-40{ }^{\circ} \mathrm{C}$. The structures were solved by direct methods (SHELX-97) and refined by fullmatrix least-squares procedures on $\mathrm{F}^{2}$ using SHELX-97. ${ }^{31}$ Hydrogen atoms were refined where possible, and otherwise added theoretically, using the riding model position parameters. Crystallographic data can be found in the Supporting Information (Table S1), CIF files can be obtained from the Cambridge Crystallographic Data Centre, CCDC-702797 (L), CCDC702796 (1), CCDC-702793 (2), CCDC-702795 (3), CCDC702794 (4), and CCDC-724089 (5). Copies of these data can be obtained free of charge from the Cambridge Crystallographic Data Centre via www.ccdc.cam.ac.uk or e-mail, deposit@ccdc. cam.ac.uk. Powder X-ray spectra were collected on a Nonius Enraf FR 590 X-ray generator with mounted Stoe StadiP using $\mathrm{Cu}$ Kalphal radiation (1.5406 $\AA$ ). IR and NMR spectra were recorded on a Bruker Tensor 27 and on a Bruker AM 360, respectively. UV-vis spectra were collected on a Perkin-Elmer Lambda 25. Fluorescence measurements were performed on a Perkin-Elmer LS 50B. TGA were recorded on a Mettler Toledo TGA7SDTA851. BET measurements were performed on a micrometrics Gemini unit. AAS measurements were done on a Shimadzu AA-6300 machine and elemental analysis performed on a EA 110 CE Instruments at the University of Basel, Switzerland.

Synthesis of $\mathbf{L},\left[\mathbf{C}_{\mathbf{2 0}} \mathbf{H}_{\mathbf{2 4}} \mathbf{O}_{7} \mathbf{N}_{\mathbf{2}}\right]$. Oxalylchloride (5.1 mL, 0.06 mol, 1.5 equiv) was dropped slowly into a suspension of nicotinic acid (5 g, $0.04 \mathrm{~mol}, 1$ equiv) in dichloromethane $(100 \mathrm{~mL})$. The mixture was then stirred overnight at room temperature. The solution was filtered, and the solid was dried under reduced pressure.

The so-obtained white nicotinic acid chloride (5.76 g, 0.04 mol, 1 equiv) was suspended in toluene $(100 \mathrm{~mL})$, and triethylamine ( $8.6 \mathrm{~mL}, 0.06 \mathrm{~mol}, 1.5$ equiv) was slowly added. The reaction mixture was refluxed for $10 \mathrm{~min}$ and allowed to cool down. A solution of tetraethylene glycol $(3.4 \mathrm{~mL}, 0.02 \mathrm{~mol}, 0.5$ equiv) in toluene was added slowly and the whole mixture was again refluxed for $8 \mathrm{~h}$ at $130{ }^{\circ} \mathrm{C}$. The brown liquid was stirred overnight at room temperature. Then, dichloromethane $(80 \mathrm{~mL})$ was added, and this phase was extracted twice with water (200 $\mathrm{mL}$ ). The organic phase was dried over $\mathrm{MgSO}_{4}$ and filtered, and the solvent was removed under reduced pressure to yield a microcrystalline powder of $\mathbf{L}$. X-ray-suitable single crystals can be grown by dissolving $\mathbf{L}$ in dichloromethane, which is allowed to evaporate at room temperature (yield 80\%).

Elem anal. $\left(\mathrm{C}_{20} \mathrm{H}_{24} \mathrm{O}_{7} \mathrm{~N}_{2}\right.$, mol. wt: 404.42), exptl (calcd, \%): C, 59.03 (59.39); H, 5.93 (5.98); N, 6.76 (6.93)\%. ${ }^{1}$ H NMR (360 $\mathrm{MHz}, \mathrm{CDCl}_{3}$, TMS, values given in ppm): $\delta 9.19$ (s, 2H, C5), $8.73(\mathrm{~d}, 2 \mathrm{H}, J=4.5 \mathrm{~Hz}, \mathrm{C} 4), 8.27(\mathrm{~d}, 2 \mathrm{H}, J=7.9 \mathrm{~Hz}, \mathrm{C} 2), 7.36$ $(\mathrm{dd}, 2 \mathrm{H}, J=4.7 \mathrm{~Hz}, J=7.9 \mathrm{~Hz}, \mathrm{C} 3), 4.46(\mathrm{t}, 4 \mathrm{H}, J=4.7 \mathrm{~Hz}, \mathrm{C} 7)$, $3.79(\mathrm{t}, 4 \mathrm{H}, J=4.6 \mathrm{~Hz}, \mathrm{C} 7), 3.64(\mathrm{~m}, 8 \mathrm{H}, \mathrm{C} 9, \mathrm{C} 10) .{ }^{13} \mathrm{C} \mathrm{NMR}$

(31) Sheldrick, G. M. SHELX-97; University of Göttingen: Göttingen, Germany, 1997. 
(90 $\mathrm{MHz}, \mathrm{CDCl}_{3}, \mathrm{TMS}$, values given in $\mathrm{ppm}$ ): $\delta 165.1$ (C6), 153.4 (C3), 150.9 (C2), 137.03 (C5), 125.8 (C1), 123.2 (C4), 70.6 (C9,C10), 68.9 (C8), 64.4 (C7). FTIR $\left(\mathrm{cm}^{-1}\right)$ : $3066(\mathrm{C}=\mathrm{C}), 2908(\mathrm{C}-\mathrm{C}), 1720(\mathrm{C}=\mathrm{O}), 1587(\mathrm{C}=\mathrm{N}), 1278$ (RCOO) $1091(\mathrm{C}-\mathrm{O})$. UV-vis (in chloroform $\lambda_{\max }, \mathrm{nm}$ ): $250 \mathrm{~nm}$

Synthesis of $L^{\prime},\left[\mathbf{C}_{\mathbf{1 4}} \mathbf{H}_{\mathbf{2 1}} \mathbf{O}_{\mathbf{6}} \mathbf{N}\right]$. The ligand $\mathrm{L}^{\prime}$ is synthesized as $\mathbf{L}$, but with a 1:1.2 ratio between the acid chloride and tetraethylene glycol. After evaporation of the solvent at reduced pressure, the remaining oil is purified by chromatography (silica gel, dichloromethane/hexane, 1:8). Yield: 40\%. The product was found to contain water, and elemental analysis reveals an equivalent of $1.5 \mathrm{H}_{2} \mathrm{O}$. We expect this to be due to strong $\mathrm{H}$ bonding between $\mathbf{L}^{\prime}$ and water, explaining why $\mathbf{L}^{\prime}$ could never be obtained as a powder.

Elem anal. $\left(\mathrm{C}_{14} \mathrm{H}_{21} \mathrm{O}_{6} \mathrm{~N} \cdot 1.5 \mathrm{H}_{2} \mathrm{O}\right.$, mol. wt: 326.34), exptl (calcd, \%): C, 51.45 (51.52); H, 7.18 (7.41); N, 4.29 (4.56). ${ }^{1} \mathrm{H}$ NMR $\left(360 \mathrm{MHz}, \mathrm{CDCl}_{3}\right.$, TMS, values given in ppm): $\delta 9.08$ $(\mathrm{s}, 1 \mathrm{H}), 8.62(\mathrm{~d}, 1 \mathrm{H}, J=3.8 \mathrm{~Hz}), 8.17(\mathrm{~d}, 1 \mathrm{H}, J=7.7 \mathrm{~Hz}), 7.28(\mathrm{dd}$, $1 \mathrm{H}, J=4.8 \mathrm{~Hz}, J=7.7 \mathrm{~Hz}), 4.73(\mathrm{~m}, 2 \mathrm{H}), 4.37(\mathrm{~d}, 2 \mathrm{H}, J=3.8 \mathrm{~Hz})$, $3.70(\mathrm{~d}, 2 \mathrm{H}, J=3.6 \mathrm{~Hz}), 3.68(\mathrm{~m}, 10 \mathrm{H}), 2.01(\operatorname{broad}, 1 \mathrm{H}) .{ }^{13} \mathrm{C}$ NMR (90 MHz, $\mathrm{CDCl}_{3}$, TMS, values given in ppm): $\delta 165.1$ (C6), $152.9(\mathrm{C} 2), 150.5(\mathrm{C} 1), 136.8(\mathrm{C} 4), 125.6(\mathrm{C} 5), 123.02$ (C3), 72.3 (C13), 70.2 (C9, C10, C11, C12), 68.1 (C8), 64.11 (C7), 61.1 (C14). FTIR $\left(\mathrm{cm}^{-1}\right): 3411$ (broad, $\left.\mathrm{O}-\mathrm{H}\right), 3037(\mathrm{C}=\mathrm{C}), 2864$ $(\mathrm{C}-\mathrm{C}), 1718(\mathrm{C}=\mathrm{O}), 1589(\mathrm{C}=\mathrm{N}), 1274(\mathrm{RCOO}), 1099(\mathrm{C}-\mathrm{O})$. $\mathrm{UV}-\mathrm{vis}$ (in chloroform $\lambda_{\max }, \mathrm{nm}$ ): $255 \mathrm{~nm}$.

Synthesis of 1, $\left.\left[\mathbf{C a}(\mathbf{L})\left(\mathrm{H}_{2} \mathrm{O}\right)_{3}\right)\right] \mathrm{I}_{2}$ and 2, $\left.\left[\mathrm{Ca}(\mathrm{L})\left(\mathrm{H}_{2} \mathrm{O}\right)_{3}\right)\right] \mathrm{I}_{2}$. $\left(\mathrm{CHCl}_{3}\right)_{2}$. Like for many isomers, it is very difficult to find appropriate conditions to crystallize only $\mathbf{1}$ or only $\mathbf{2}$. Since $\mathbf{1}$ crystallizes much better, it is very difficult to obtain a pure batch of crystals of $\mathbf{2}$. Generally, compound $\mathbf{2}$ crystallizes better when the mother liquor is left to stand at $-24{ }^{\circ} \mathrm{C}$, while evaporation and diffusion techniques at room temperature afford only compound $\mathbf{1}$.

Synthesis of 1, $\left.\left[\mathbf{C a}(\mathbf{L})\left(\mathrm{H}_{2} \mathrm{O}\right)_{3}\right)\right] \mathrm{I}_{2}$. Ligand $\mathbf{L}(0.4 \mathrm{~g}, 1 \mathrm{mmol}, 1$ equiv) and $\mathrm{CaI}_{2}(0.32 \mathrm{~g}, 1 \mathrm{mmol}, 1$ equiv) are dissolved together in chloroform $(20 \mathrm{~mL})$. The solution is stirred overnight at room temperature. The yellow reaction mixture is then filtered, and the filtrate is allowed to evaporate slowly at room temperature. After one week, yellow crystals of 1 grow (yield $60 \%$ ).

For scaleup, $\mathbf{L}$ ( 2 g, 5 mmol, 1 equiv) and $\mathrm{CaI}_{2}$ (1.15 g, 5.2 mmol, 1.2 equiv) are dissolved together in a minimum amount of chloroform (around $60 \mathrm{~mL}$ ). The solution is stirred overnight at room temperature. The precipitation is forced by adding hexane; then, the solution is filtered and washed with chloroform and acetone. The bulk material is characterized by powder diffraction.

FTIR $\left(\mathrm{cm}^{-1}\right): 3321(\mathrm{OH}), 3032(\mathrm{C}=\mathrm{C}), 2966(\mathrm{C}-\mathrm{C}), 1724$ $(\mathrm{C}=\mathrm{O}$, “in”), $1697(\mathrm{C}=\mathrm{O}$, "out"), $1595(\mathrm{C}=\mathrm{N}), 1282(\mathrm{RCOO})$, $1060(\mathrm{C}-\mathrm{O})$. Elem anal. $\left(\mathrm{CaI}_{2} \mathrm{C}_{20} \mathrm{H}_{30} \mathrm{~N}_{2} \mathrm{O}_{10}\right.$, mol. wt. 752.34), exptl (calcd, \%): C, 31.93 (31.93); H, 4.30 (4.02); N, 3.81 (3.72)\%.

Since in solution both compounds $\mathbf{1}$ and $\mathbf{2}$ are equal, the analyses in solution were drawn together.

Synthesis of 2, $\left.\left[\mathbf{C a}(\mathbf{L})\left(\mathrm{H}_{2} \mathrm{O}\right)_{3}\right)\right] \mathrm{I}_{2} \cdot\left(\mathrm{CHCl}_{3}\right)_{2}$. Ligand $\mathbf{L}(0.4 \mathrm{~g}, 1$ mmol, 1 equiv) and $\mathrm{CaI}_{2}(0.32 \mathrm{~g}, 1 \mathrm{mmol}, 1$ equiv) are dissolved in chloroform $(20 \mathrm{~mL})$. The solution is stirred overnight at room temperature. The yellow reaction mixture is then filtered, and the filtrate is allowed to stand in the refrigerator at $-24^{\circ} \mathrm{C}$. After a few days, nice pale yellow temperature-sensitive crystals grow (yield 40\%).

FTIR $\left(\mathrm{cm}^{-1}\right): 3334(\mathrm{OH}), 3070(\mathrm{C}=\mathrm{C}), 2939(\mathrm{C}-\mathrm{C}), 1735$ $(\mathrm{C}=\mathrm{O}), 1598(\mathrm{C}=\mathrm{N}), 1276(\mathrm{RCOO}) 1065(\mathrm{C}-\mathrm{O})$.

Analysis of Solutions of Compounds 1 and 2. For NMR measurements, complexes $\mathbf{1}$ and $\mathbf{2}$ were each directly dissolved in $\mathrm{CDCl}_{3}$ and give thus identical NMR spectra.

${ }^{1} \mathrm{H} \mathrm{NMR}\left(360 \mathrm{MHz}, \mathrm{CDCl}_{3}\right.$, TMS, values given in $\left.\mathrm{ppm}\right): \delta 9.18$ $(\mathrm{s}, 2 \mathrm{H}), 8.72(\mathrm{~d}, 2 \mathrm{H}, J=3.4 \mathrm{~Hz}), 8.24$ (broad, $2 \mathrm{H}), 7.33$ (dd, $2 \mathrm{H}, J=4.9 \mathrm{~Hz}, J=7.7 \mathrm{~Hz}$ ), 4.44 (broad, 4H), 3.77 (broad, 4H), 3.62 (m, 8H), 1.72 (broad, water). ${ }^{13} \mathrm{C}$ NMR $(90$ $\mathrm{MHz}, \mathrm{CDCl}_{3}$, TMS, values given in ppm): $\delta 164.9$ (C6), 153.2 (C3), 150.7 (C2), 137.03 (C5), 125.7 (C1), 123.2 (C4), 70.5 (C9, $\mathrm{C} 10), 68.9$ (C8), 64.3 (C7). UV-vis (in chloroform $\lambda_{\max }, \mathrm{nm}$ ): 368 .

Synthesis of 3, $\left\{\left[\mathbf{C u}_{\mathbf{4}} \mathbf{I}_{\mathbf{4}}(\mathbf{L})_{2}\right]\left(\mathrm{H}_{2} \mathrm{O}\right)_{2}\right\}_{\mathrm{n}}$. CuI $(0.25 \mathrm{~g}, 2 \mathrm{mmol}, 2$ equiv) is suspended in chloroform $(20 \mathrm{~mL})$. After the addition of $\mathbf{L}(0.4 \mathrm{~g}, 1 \mathrm{mmol}, 1$ equiv), the gray suspension clarifies in a few minutes to a yellow solution. The mixture is stirred overnight and is layered with hexane. After a few days, big rhombic crystals grow from the solution (yield $80 \%$ ).

Elem anal. ( $\left[\mathrm{Cu}_{2} \mathrm{I}_{2} \mathrm{C}_{20} \mathrm{H}_{24} \mathrm{~N}_{2} \mathrm{O}_{7}\right]_{2}$, Mol. Wt. 1570.641), exptl (calcd, \%): C, 30.27 (30.58); H, 3.06 (3.08); N, $3.31(3.56) \% .{ }^{1} \mathrm{H}$ NMR (360 MHz, $\mathrm{CDCl}_{3}$, TMS, values given in ppm): $\delta 9.46$ (broad, 2H), 8.79 (broad, $2>\mathrm{H}), 8.30(\mathrm{~d}, 2 \mathrm{H}, J=7.7 \mathrm{~Hz}), 7.44$ $(\mathrm{s}, 2 \mathrm{H}), 4.46(\mathrm{t}, 4 \mathrm{H}, J=4.3 \mathrm{~Hz}), 3.79(\mathrm{t}, 4 \mathrm{H}, J=3.8 \mathrm{~Hz}), 3.65(\mathrm{~m}$, $8 \mathrm{H}) .{ }^{13} \mathrm{C} \mathrm{NMR}\left(90 \mathrm{MHz}, \mathrm{CDCl}_{3}, \mathrm{TMS}\right.$, values given in ppm): $\delta$ 164.7 (C6), 153.7 (C3), 151.1 (C2), 137.5 (C5), 125.1 (C1), 70.7 (C9, C10), $68.9(\mathrm{C} 8), 64.7(\mathrm{C} 7)$. FTIR $\left(\mathrm{cm}^{-1}\right): 3085(\mathrm{C}=\mathrm{C}), 2875$ $(\mathrm{C}-\mathrm{C}), 1722(\mathrm{C}=\mathrm{O}), 1598(\mathrm{C}=\mathrm{N}), 1288(\mathrm{RCOO}) 1111(\mathrm{C}-\mathrm{O})$. $\mathrm{UV}$-vis (in chloroform $\lambda_{\max }, \mathrm{nm}$ ): 268 .

Synthesis of 4, $\left[\mathrm{CaCu}_{3}(\mathbf{L}) \mathrm{I}_{5}\left(\mathrm{H}_{2} \mathrm{O}\right)_{2}\right]$. Ligand $\mathbf{L}(0.2 \mathrm{~g}, 0.5 \mathrm{mmol}$, 1 equiv) and $\mathrm{CaI}_{2}(0.14 \mathrm{~g}, 0.5 \mathrm{mmol}, 1$ equiv) are dissolved in dichloromethane $(10 \mathrm{~mL})$ and acetonitrile $(10 \mathrm{~mL})$ and stirred for a few hours. In small portions, $\mathrm{CuI}(0.24 \mathrm{~g}, 0.5 \mathrm{mmol}, 3$ equiv) is added, and the mixture is stirred overnight. The solution is filtered and allowed to evaporate slowly. After a few weeks, nice yellow crystals grow $(50 \%)$.

For the bulk synthesis and scaleup, $\mathbf{L}(2 \mathrm{~g}, 5.0 \mathrm{mmol}, 1$ equiv $)$ and $\mathrm{CaI}_{2}$ (1.4 g, $5 \mathrm{mmol}, 1$ equiv) are dissolved in a minimum of absolute dichloromethane (ca. $60 \mathrm{~mL}$ ) and stirred for $12 \mathrm{~h} . \mathrm{CuI}$ ( $2.82 \mathrm{~g}, 10 \mathrm{mmol}, 3$ equiv) is dissolved in a mixture of $1: 1$ dichloromethane/acetonitrile and added. The solution is stirred overnight, and a precipitate forms. To the reaction mixture, diethyl ether and $n$-hexanes are added to complete the precipitation. The powder is filtered and washed several times with ethanol to dissolve unreacted starting material; then, it is dried in a vacuum. The bulk material is characterized by powder diffraction and confirmed to be compound 4 .

${ }^{1} \mathrm{H}$ NMR (360 MHz, $\mathrm{CDCl}_{3}$, TMS, values given in ppm): $\delta$ $9.34(\mathrm{~s}, 2 \mathrm{H}), 8.98(\mathrm{~s}, 2 \mathrm{H}), 8.32(\mathrm{~d}, 2 \mathrm{H}, J=7.9 \mathrm{~Hz}), 7.45(\mathrm{dd}, 2 \mathrm{H}$, $J=4.9 \mathrm{~Hz}, J=7.0 \mathrm{~Hz}), 4.50(\mathrm{t}, 4 \mathrm{H}, J=4.5 \mathrm{~Hz}), 3.83(\mathrm{~d}, 4 \mathrm{H}, J=4.3$ $\mathrm{Hz}), 3.68$ (m, 8H), 1.66 (broad, water). ${ }^{13} \mathrm{C}$ NMR $(90 \mathrm{MHz}$, $\mathrm{CDCl}_{3}$, TMS, values given in ppm): $\delta 164.9$ (C6), 153.7 (C3), 151.2 (C2), 137.5 (C5), 125.7 (C1), 123.6 (C4), 70.7 (C9, C10), 69.0 (C8), 64.7 (C7). Elem anal. of the bulk powder ([CaCu $\left.3\left(\mathrm{C}_{20} \mathrm{H}_{28} \mathrm{O}_{9} \mathrm{~N}_{2}\right) \mathrm{I}_{5}\right]$, mol. wt. 1305.68), exptl (calcd) (\%): C, 18.25 (18.40); H; 2.36 (2.16); N, 2.34 (2.14)\%. FTIR $\left(\mathrm{cm}^{-1}\right)$ : $3395(\mathrm{OH}), 3060(\mathrm{C}=\mathrm{C}), 2946(\mathrm{C}-\mathrm{C}), 1709(\mathrm{C}=\mathrm{O}), 1597$ $(\mathrm{C}=\mathrm{N}), 1287(\mathrm{RCOO}), 1081(\mathrm{C}-\mathrm{O})$. UV-vis (in chloroform $\left.\lambda_{\max }, \mathrm{nm}\right): 253,372$.

Synthesis of 5, $\left\{\left[\mathrm{Ba}_{2} \mathrm{Cu}_{3}\left(\mathbf{L}^{\prime}\right)_{4} \mathrm{I}_{7}\right]\left(\mathrm{CH}_{2} \mathrm{Cl}_{2}\right)_{3}\right\}_{\mathrm{n}}$. CuI (0.6 g, 0.5 mmol, 3 equiv) and $\mathrm{BaI}_{2}(0.4 \mathrm{~g}, 0.25 \mathrm{mmol}, 1$ equiv) are dissolved in absolute dichloromethane or chloroform $(30 \mathrm{~mL})$. Ligand $\mathbf{L}^{\prime}$ ( $0.6 \mathrm{~g}, 0.5 \mathrm{mmol}, 2$ equiv) in a minimum of solvent is dropped into the solution, and the mixture is stirred overnight. A majority of $\mathbf{5}$ precipitates, is filtered off, and is washed with dichloromethane. The mother liquor is layered with $n$-hexanes and cooled to $4{ }^{\circ} \mathrm{C}$ to obtain crystals (yield $55 \%$ ).

For the bulk synthesis, the mother liquor is mixed with diethyl ether and hexane to force precipitation.

Elem anal. of the solvent-free, dried bulk material obtained from precipitation with $n$-hexanes $\left(\left[\mathrm{C}_{56} \mathrm{H}_{84} \mathrm{~N}_{4} \mathrm{O}_{24} \mathrm{Ba}_{2} \mathrm{Cu}_{3} \mathrm{I}_{7}\right]\right.$, mol wt. 2550.87), exptl (calcd, \%): C, 26.48 (26.37); H, 3.11 (3.31); N, 2.05 (2.19)\%. ${ }^{1} \mathrm{H}$ NMR (360 MHz, $\mathrm{CDCl}_{3}$, TMS, values given in ppm): $\delta 9.59$ (broad), 9.13 (broad), $8.37(1 \mathrm{H})$, $7.52(1 \mathrm{H}), 4.50(2 \mathrm{H}), 4.35$ (broad), $3.83(2 \mathrm{H}) 3.68(\mathrm{~m}, 10 \mathrm{H}), 2.01$ (1H). FTIR $\left(\mathrm{cm}^{-1}\right): 3296$ (weak, $\left.\mathrm{O}-\mathrm{H}\right), 3033(\mathrm{C}=\mathrm{C}), 2902$ $(\mathrm{C}-\mathrm{C}), 1704(\mathrm{C}=\mathrm{O}), 1596(\mathrm{C}=\mathrm{N}), 1301 \quad(\mathrm{RCOO}), 1080$ $(\mathrm{C}-\mathrm{O})$. $\mathrm{UV}-\mathrm{vis}$ (in chloroform $\lambda_{\max }, \mathrm{nm}$ ): $359 \mathrm{~nm}$. 
Acknowledgment. The authors thank the Swiss National Science Foundation and the University of Fribourg and FriMat for most generous support. We also thank Helen Stöckli-Evans and Antonia Neels (University of Neuchatel) for help with the X-ray structure, Anne Schuwey (University of Fribourg) for large-scale synthesis of ligands, and Vikash Malik (University of Fribourg) for the BET measurement.
Supporting Information Available: A crystallographic table for all six compounds ( $\mathbf{L}, \mathbf{1}, \mathbf{2}, \mathbf{3}, \mathbf{4}$, and 5); additional packing pictures for $\mathbf{1}, \mathbf{2}$, and $\mathbf{4}$; TGA spectra of 3 and $\mathbf{4}$; spectroscopic data of $\mathbf{1}, \mathbf{2}, \mathbf{3}, \mathbf{3}^{\prime}, \mathbf{4}$, and $\mathbf{5}$; BET hysteresis curves of $\mathbf{3}$; a picture of the fluorescing compounds $\mathbf{3}$ and $\mathbf{3}^{\prime}$; the powder X-ray spectra for 6 after combustion; and also tables for $\mathrm{H}$ bonds in 1, 2, 4, and 5 are deposited. 